\title{
Because there was a cause for concern: An investigation into the word-specific prediction account of the implicit-causality effect.
}

\author{
Cara Featherstone
}

MSc Psycholinguistics

The University of Edinburgh

2007 


\section{Abstract}

In Koornneef and Van Berkum's (2006) recent eye-tracking study of implicitcausality effect (Caramazza, Grober, Garvey, \& Yates, 1977), mid-sentence delays were observed in the processing of sentences such as 'David blamed Linda because $s h e_{\text {(bias-consistent) }} / h_{(\text {bias-inconsistent)...' when the pronoun following because was }}$ inconsistent with the bias of the implicit-causality verb. The authors suggested that these delays could be attributed to participants having predicted the occurrence of a bias-consistent pronoun after because. Accordingly, any word other than the biasconsistent pronoun placed after because should cause processing delays. The present investigation set out to test this speculation by presenting participants with sentences of the form 'David blamed Linda because she $_{(\text {bias-consistent })} /$ he $_{(\text {bias-inconsistent })} /$ there $_{\text {(bias- }}$ neutral)...'. Since significant delays were observed in sentences containing a biasinconsistent pronoun but not in sentences containing there, the results of the present study did not support a word-specific prediction-based account. These implications of these findings are discussed with regards both to the nature of online predictions in discourse processing. 


\section{Contents}

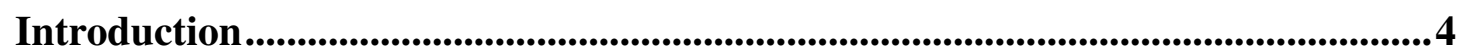

Early probabilistic models of language processing: origins and challenges..............5

Continued evidence for predictions in language comprehension .............................6

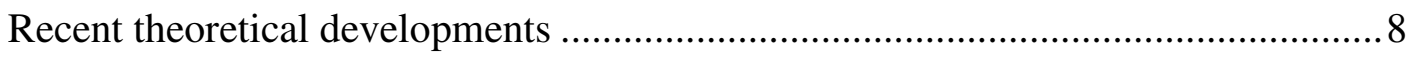

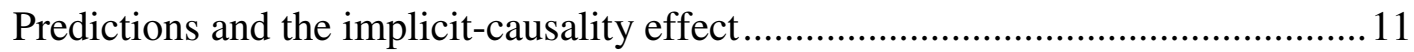

Investigating the word-specific prediction account of the implicit-causality effect 13

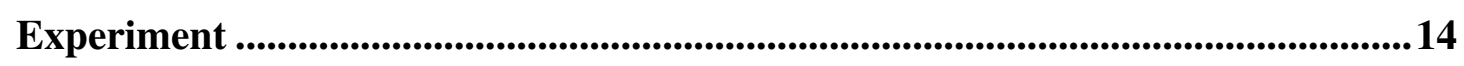

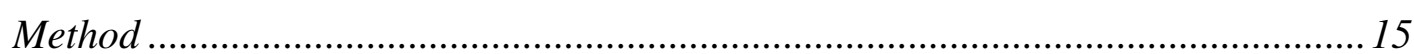

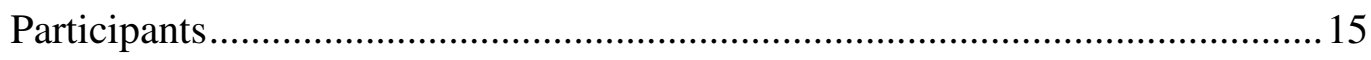

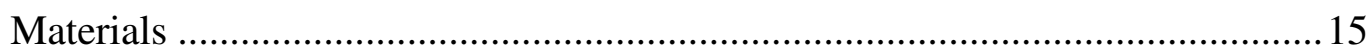

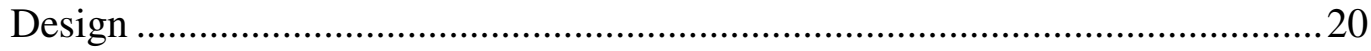

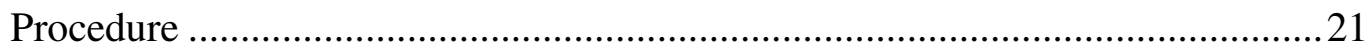

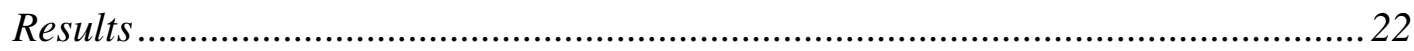

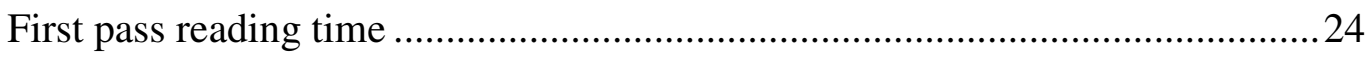

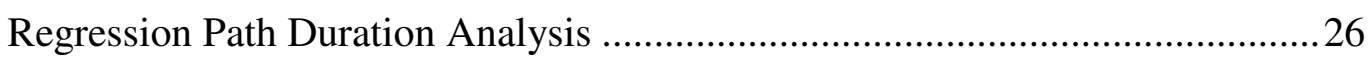

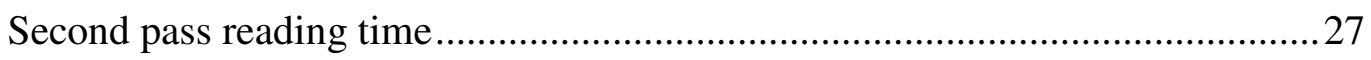

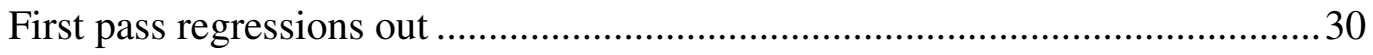

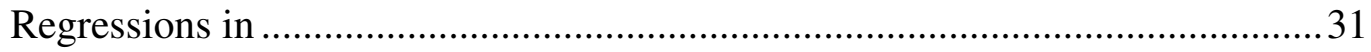

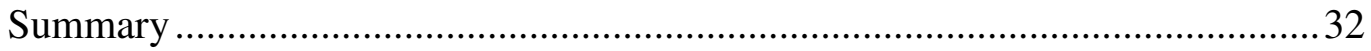

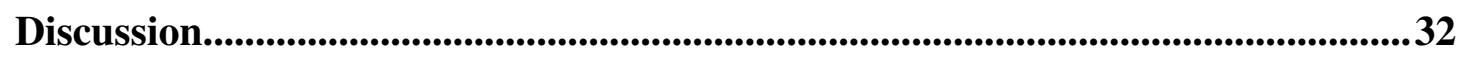

Implications of the present investigation's findings for the word-specific prediction

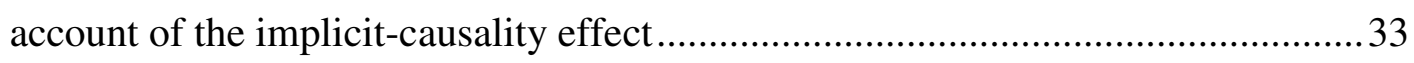

Accessibility account and implicit-causality effect ...............................................34

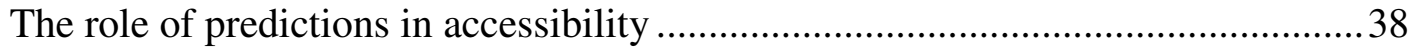

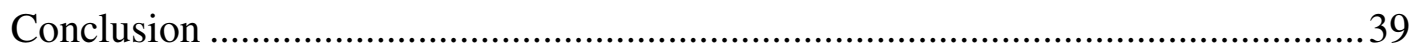

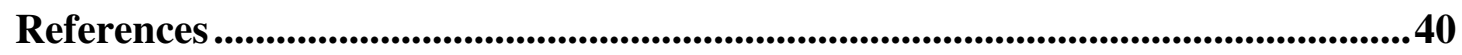

Appendix - Experimental items ................................................................................................46 
Evidence supporting online predictions and context-based facilitation in language comprehension has been found in broad range of investigations, from discourse studies (e.g. Finsher-Keifer, 1993; Weingartner, Guzman, Levine, \& Klin, 2003) to word recognition studies (Duffy, Henderson, \& Morris, 1989; Hoeks, Stowe, \& Deodens, 2004), through the observation of dialogues (e.g. Sachs, Schegloff, \& Jefferson, 1974; Pickering, \& Garrod, 2004), Event-Related-Potentials (e.g. Kutas, \& Hillyard, 1984; Hagoort, 2003b) and eye-tracking data (e.g. Ehrlich, \& Rayner, 1981; Kamide, Altmann, \& Haywood, 2003). Recently, some of the most prominent work in this area has been carried out by Van Berkum and colleagues (e.g. Van Berkum, Zwisterlood, Brown, \& Hagoort, 2003; Van Berkum, Brown, Zwisterlood, Kooijman, \& Hagoort, 2005; Koornneef, \& Van Berkum, 2006) with a particular focus on the cognitive implications of the violation of expectancies during language comprehension.

One of Van Berkum's most recent collaborations (Koornneef, \& Van Berkum, 2006) used both self-paced reading and eye-tracking data to investigate the processing of sentences containing an implicit-causality bias. The term implicit causality was first used by Caramazza, Grober, Garvey and Yates (1977) to describe verbs such as praise and amuse which "supply information about whose behaviour or state is the more likely immediate cause of the event at hand" (Koornneef, \& Van Berkum, 2006, 446). This information, which is intrinsic to the verb itself (Crinean, \& Garnham, 2006), results in a bias in which of the two characters mentioned in connection with the verb is most likely to be mentioned in an explanation of the described event. For instance, if John praises Mary, it will most likely be because of something Mary did. On the other hand, if John amuses Mary, it will most likely be because of something John did. The data collected in Koornneef and Van Berkum's (2006) eye-tracking study showed that significant mid-sentence delays occurred in the reading of sentences containing a bias-inconsistent pronoun (i.e; John praised Mary because he...). Relying on the assumption that eye-tracking data is indicative of moment-tomoment processing in reading (Rayner, \& Pollatsek, 2006), this replication of the implicit-causality effect demonstrated first of all that it is harder to process sentences containing a pronoun which is inconsistent with the bias of the main verb than it is to process sentences containing a pronoun which is consistent with that same bias. Secondly, the data in this study also supported an early-integration account of the implicit-causality effect (see Greene, \& McKoon, 1995; Long, \& De Ley, 2000), since 
the reading delays were observed on words immediately following the biasinconsistent pronoun rather than at the very end of the sentence, as a late-integration account of the implicit-causality effect had previously suggested the delays would be (see Garnham, 2001; Stewart, Pickering, \& Sanford, 2000).

In contrast to the strengths of these conclusions, the following speculation concerning the cognitive processes underlying these processing delays remains controversial.

"Implicit causality is on par with a wide range of other sources of information that have been shown to affect the comprehension process very rapidly. We know that the meaning of verbs like ate and told allow listeners to anticipate specific upcoming verb arguments (e.g. Altmann \& Kamide, 1999; Nieuwland \& Van Berkum, in press). We also know that sentential as well as wider discourse context can support the prediction of specific upcoming words (Otten \& Van Berkum, 2004, Van Berkum et al., 2005; Wicha et al., 2004). In view of these phenomena, what would be so special about, say, anticipating a specific upcoming referent or pronoun after having read 'David praised Linda because?"” (Koornneef, \& Van Berkum, 2006, p 461).

It is this statement by Koornneef and Van Berkum (2006) which has prompted the present investigation. Before the veracity of this speculation can be addressed, a survey of the literature surrounding the notion of online predictions in language comprehension will be carried out, in order to ground the present study in the latest theoretical developments of this recently resuscitated and heavily debated area of psycholinguistics (Jurafsky, 2003).

\section{Early probabilistic models of language processing: origins and challenges}

The notion that predictability eases the processing of words during sentence comprehension had already long been suggested within the field of psycholinguistics, and can be traced back to Wilson and Carroll's (1954) application of a Markov chain to models of language comprehension. In the words of Shannon and Weaver (1949), "a system which produces a sequence of symbols according to certain probabilities is called a stochastic process, and the special case of a stochastic process in which the 
probabilities depend upon the previous events is called a Markov process or a Markov chain" (p. 6). Each new element in a chain thus reduces the degrees of freedom for potential upcoming events. This is equated with adding information, and reducing entropy, the degree of uncertainty associated with a random variable.

In order to apply this probabilistic approach to language comprehension, Wilson and Carroll (1954) developed a morphological, phonological and syntactic grammar made of finite disjunctive options. Within this grammar, the entropy reduction, or downward change in average uncertainty, which results from the addition of a word to a sentence fragment, forms the basis of the predictability of upcoming structures. This approach is widely used in speech-recognition systems (Mark, Miller \& Grenander, 1994), which rely on the regularities in strings of words to predict or disambiguate words on a local level. However, despite its strengths for the modelling of artificial languages, this approach was criticised for its inability to account for the complexity of human language, since it fails to provide a means of modelling its hierarchical nature (Mark, Miller \& Grenander, 1994).

A second source of criticism of the probabilistic theorisation of language processing came, according to Van Berkum et al. (2005) from the influence of Chomsky's theory of generative grammar. From Syntactic Structures (1957) to Minimalism (1995), the underlying idea of Chomsky's school of though has been that of language as an innate, biologically pre-programmed and species-specific preprogrammed faculty which is independent from other cognitive structures (Harley, 2000). This faculty, which relies on the use of a grammar, defined by Harley (2000, p 33) as "a formal device that uses a finite number of rules which in combination can generate all sentences in a language", has the propensity to create an infinite number of syntactically correct strings. Though recent probabilistic models of language have overcome the problems associated with an infinite number of syntactically plausible strings (see Hale, 2001; Levy, 2005), according to Jackendoff (2002), Chomsky's (1957) demonstration of an infinite number of possible sentence continuations posed a serious challenge to the plausibility of a probabilistic approach to language processing.

\section{Continued evidence for predictions in language comprehension}

However, despite these two potential threats to the credibility of probabilistic models of language processing, many studies continued to converge on their 
plausibility from a broad range of both theoretical and methodological stances, the range of which was described at the onset of the present report. Altmann and Kamide (1999) for instance used a cross-modal eye-tracking study to establish the point in a sentence at which participants were able to predict the development of a sentence in a listening task. Participants were given a simple visual scene to inspect while they heard a sentence like 'The boy will move the cake'. The scene featured a target object (cake) and several distracter objects (non-edible objects). Participants' eyes consistently moved to the picture of a referent which would fit with the verb they had just heard. Results therefore showed that participants were able to use information from the verb to predict which type of object would be referred to next (i.e. an edible object after eat) and to pre-select appropriate continuations from within a finite set of options (Altmann, \& Kamide, 1999). Predictions seem however not to be limited to situations in which the meaning of a verb allows the selection of an argument from within a finite set of pre-seen alternatives, since dialogue studies have demonstrated that interlocutors are able to finish each-others' sentences (Pickering \& Garrod, 2004).

The key to understanding this apparent discrepancy between what is theoretically plausible and what has been observed lies in the previously mentioned fact that language consists of more than just syntax (Van Berkum et al, 2005). Mark et al. (1994) strongly emphasised this point in their rationale for the construction of a model of language comprehension which encompassed both hierarchical phrase structure models and lexical neighbourhood parameters. Using as example the phrases "the red dog" and "the red car" the authors pointed out that within a syntax-only (tree) model, both phrases have equal an equal likelihood of occurring in natural language. However, when the lexical bigram (chain) constraints are added, "the red dog" becomes a much less likely occurrence than "the red car" (Mark, Miller \& Grenander, 1994), because, within the vocabulary of the model, red is used much less frequently in association with $\operatorname{dog}(2)$ than it is in association with car (18). The significant reduction in entropy reported by the authors in a mixed tree/chain diagram compared to in a bigram-only or a tree-only model (Mark et al, 1994) strongly supports the nowadays widely accepted importance of combining lexical and syntactic information for when predicting upcoming words in a string (see Roark, 2001 for a more recent probabilistic lexicalised model). The acknowledgement of the necessity of integrating semantic, syntactic and lexical information into probabilistic models of language processing (Kang, Wang, Greiner, Schuurmans \& Cheng, 2004) brings into focus 
what Mark, Miller and Grenander (1994) referred to as the "lexical information inherent in Markov models" (Mark et al, 1994, p. 1), distinguishing models of natural language processing from purely syntactic models. The recent addition of probabilistic latent semantic analysis to this type of model has recently been seen in a successful Markov-type model of human language (Kang et al, 2004), emphasising the necessity of incorporating multiple sources of information into any probabilistic model of human language processing.

Finally, the importance of knowledge regarding the nature of events described in discourse was also emphasised by McRae, Spivey and Tannenhaus (1998) in a series of completion tasks and self-paced reading experiments. It was demonstrated that knowledge about the nature of events in which discourse entities or participants were involved clearly influenced the processing of syntactically ambiguous sentences. Zwaan and Radvansky's (1998) review of the literature surrounding situation models also seemed to depict world knowledge as a basis for predicting upcoming information, making word-knowledge and situation models another key component in models of prediction in language comprehension.

\section{Recent theoretical developments}

In an attempt to unify to capture the nature of probabilistic predictions in language comprehension, a new wave of research has recently emerged, investigating the notion of surprisal, defined as "an alternate term in information theory for the information value of the word" (Jurafsky, 2003, p. 27). Mathematically speaking, surprisal corresponds to the negative log of a word's probability given the context in which this word occurs; psychologically speaking, it is assumed to be related to the cognitive effort necessary for the integration of the next word into a parse (Jurafsky, 2003). Though these definitions seem at first equivalent, their different emphases reflect two different understandings of the cognitive processes responsible for increased difficulty on less predictable words.

Basing his theorisation upon the first of these two approaches, Hale (2001), proposed a probabilistic model in which " $n-1$ words of history serve as the basis for predicting the $\mathrm{n}^{\text {th }}$ word" (Hale, 2001, $\mathrm{p} 2$ ). In a later formulation, the author equated this mathematically expressed description of surprisal with the notion of an incremental processing of a sentence which gradually narrows down the possibilities for each up-coming word (Hale, 2003). Hale's (2006) Entropy Reduction Hypothesis 
(ERH) states that "a person's processing difficulty at a word in a sentence is proportional to the number of bits signalled to the person by that word with respect to a probabilistic grammar that the person knows"(Hale, 2006, p. 650). Within this most recent approach, the author created a complexity matrix of sentence comprehension by calculating the conditional entropy of a mildly context-sensitive grammar constrained by an initial sentence string. According to this model, the more certainty a reader or listener has as to the nature of upcoming information, the more difficulty will be experienced should the target word differ from the expected word, because of the necessary redistribution of entropy on occurrence of the unexpected word.

Building upon Hale's (2001) work, Levy (2005) set out to "provide a new information-theoretic derivation of a parallel, expectation-based model" ( $\mathrm{p} 24$ ) which would connect, under one unifying theory, "robust processing, disambiguation, inference and processing difficulty" (p 33). His model is described as follows: "The possible structural analyses of a partial input are preferentially ranked in parallel, and the difficulty of a new word corresponds to the amount of reallocation necessary to reflect the word's effect on the preference ranking" (p 27). Thus, the processing difficulty experienced by readers of listeners which results in a surprisal effect is, within this probabilistic model, equated with the difficulty of replacing the old distribution with the new" (Levy, 2005, p 32).

Returning to the depiction of surprisal as the cognitive effort necessary for the integration of the next word into a parse (Jurafsky, 2003), it must be noted that the correct prediction of an upcoming word is not the only reason for facilitated processing. Within his original formulation of surprisal, Hale (2001) stated that that "a language model helps a speech recogniser focus its attention on words that are likely continuations of what it has recognised so far" (Hale, 2001, p 1). This focussing of attention could, as explained above, call upon probabilities within semantics, syntax, lexical information and world-knowledge (Mark et al, 1994; McRae et al, 1998) to facilitate the post-lexical integration of a word into the both the grammatical structure of the sentence so far and the discourse in which the word appears.

This uncertainty as to whether the surprisal effect, namely the increased processing difficulty on words which are arguably less predictable, should be attributed to the use of online predictions during sentence processing or to an easier post-lexical integration of words into the current discourse, has been maintained by an 
all-pervading methodological caveat. Many of the previously mentioned investigations relied on a probe-word methodology. This experimental approach requires participants to react to a target word as quickly as possible, be that by naming it or by making a lexicality judgment on it (Van Berkum et al, 2005). Since words which could be inferred from a given context demanded less cognitive processing effort than unrelated words, researchers concluded that participants had predicted upcoming words from their context. However, this claim was merely speculative, as the methodology only enabled the observation of participants' behaviour once they had encountered the target word. Consequently, the results could have been due equally to the context-based facilitation of post-lexical integrations as to online predictions (Van Berkum et al, 2005).

Van Berkum et al. (2005) were amongst the first psycholinguists to both recognise and respond to this potential confound. In a series of Dutch ERP experiments, Van Berkum et al. (2005) made use of the gender markings of adjectives, to establish whether the relative ease with which 'predictable' words were processed could be attributed to participants having identified the target word prior to encountering it. A typical example of the materials used in this investigation is presented below (Van Berkum et al., 2005, p 446).

De inbreker had geen enkele moeite de geheime familiekluis te vinden. [The burglar had no trouble locating the secret family safe.]

- Deze bevond zich natuurlijk achter een grootneu maar onopvallend schilderijneu. [Of course, it was situated behind a big-neutral but

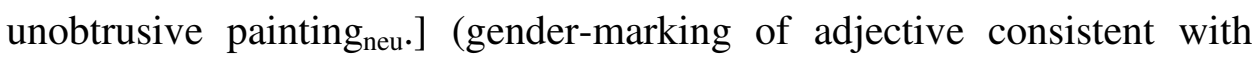
predicted word)

- Deze bevond zich natuurlijk achter een grotecom maar onopvallende boekenkastcom. [Of course, it was situated behind a big-com but

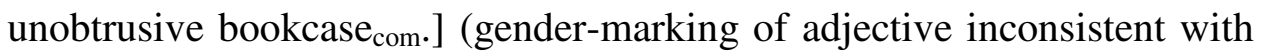
predicted word)

The reasoning behind the experiments was as follows: "if readers indeed predict a specific noun by the time they have heard the prediction-supporting story up to the indefinite article, an inconsistently gender-inflected adjective should be an unpleasant surprise, and the processing consequences of this perturbation might show 
up as an ERP effect at the adjective" (Van Berkum et al, 2005, p 446). The ERP data from this series of experiments showed disrupted processing on adjectives prior to the target when these adjectives presented a gender inflection which was inconsistent with the word participants were expected to predict from the context. Consequently, the authors concluded that the investigation provided evidence in favour of the existence of rapid online lexical predictions during the processing of fluent discourse (Van Berkum et al, 2005).

\section{Predictions and the implicit-causality effect}

It was with this investigation in mind that Koornneef and Van Berkum (2006) set out to investigate the role of prediction in the long-recognised delays associated with the processing of a bias-inconsistent pronoun in an implicit-causality context (Caramazza, et al., 1977). Koornneef and Van Berkum (2006) used eye-tracking and self-paced reading to investigate "mid-sentence reading delays caused by pronouns that are inconsistent with the bias of a preceding implicit causality verb" ( $p$ 445). As explained in the opening paragraphs of this introduction, implicit-causality verbs present a bias in terms of which of the two characters mentioned in connection of the verb is usually held responsible for the event at hand. Consequently, the sentences used in Koornneef and Van Berkum's (2006) investigation were categorised either as 'consistent' (i.e. David praised Linda because she...) or 'inconsistent' (i.e. David praised Linda because he...) with the verb bias, and all contained a second clause which enabled the construction of a coherent explanation for the event at hand. Since significant delays were observed in the processing of sentences after the critical pronoun in 'inconsistent' sentences compared to 'consistent' sentences, the data of this recent experiment clearly replicated the implicit-causality effect. Moreover, since the delay occurred early in the processing of the second clause of the sentence, Koornneef and Van Berkum (2006) argued for an early prediction effect rather than for a late integration effect (see Garnham, 2001 and Stewart et al, 2000 for a late integration account of the implicit-causality effect).

Though the data collected during this investigation clearly supported the presence of processing difficulties in 'inconsistent' sentences and an early effect of the implicit-causality bias, their previously mentioned speculation as to the processes underlying these difficulties was somewhat controversial. Koornneef and Van Berkum (2006) suggested that the relative ease with which 'consistent' sentences 
were processed could be attributed to "the prediction of specific upcoming words" ( $p$ 461 ), and in this case, to the prediction of the bias-consistent pronoun. Since the processing difficulties were recorded after the participants had read the critical element (i.e. the bias-consistent or bias-inconsistent pronoun), this study was ultimately prone to the same potential confounds as the probe-word investigations previously criticised by Van Berkum et al. (2005). Consequently, the methodology employed in their investigation was unable to exclude an alternative post-lexical facilitation explanation for these mid-sentence delays. One such explanation revolves around the notion of antecedent accessibility.

Accessibility, equated with the extent to which the antecedent of an anaphoric expression is active in memory (Arnold, 1998), is intrinsically tied to the amount of difficulty associated with the processing of any given pronoun during sentence comprehension. In line with Sperber and Wilson's (1986) relevance theory, which posits a necessary balance between cognitive function and processing cost, pronouns, which contain very little information about their antecedent mark a high degree of antecedent accessibility (Ariel, 1990). They are consequently most commonly used to refer to the most salient discourse entity (Almor, 1999). In a corpus-based study, Arnold (2001) found that "the accessibility of a given referent, which can be modelled in terms of the activation of its representation, is driven by the likelihood that it will be referred to again in the following discourse" ( $p$ 154). On reading the connector because, participants "construct a causal connection between the previous event and the incoming event" (Zwaan \& Radvansky, 1998, p 171). This would typically be achieved by resorting to world knowledge as to who would usually be held responsible for the event at hand. Since implicit-causality verbs provide information as to which of the two people associated with the described event will feature in an explanation of said event, it is not surprising that "implicit causality primarily impacts pronoun resolution when the following clause is introduced with a because connector" (Arnold, 2001, p 138). The relative ease with which the 'predictable' pronoun was processed in Koornneef and Van Berkum's (2006) investigation could therefore be accounted for simply by the fact that the antecedent to that pronoun was signalled by the verb bias as the most likely person to be referred to after the word because and was therefore maintained more active than the antecedent to the bias-inconsistent pronoun. Since pronouns which refer to antecedents which are highly active or focussed in the mind of the reader are easier to process than those referring non- 
focussed antecedents (Garrod, Greudenthal, \& Boyle, 1994), this account could explain the data collected by Koornneef and Van Berkum (2006) just as well as their speculation of a word-specific prediction of a bias-consistent pronoun after because does.

In sum, the eye-tracking data reported by Koornneef and Van Berkum (2006) cannot distinguish between the following two possibilities: (a) as suggested by the authors, participants process the rest of the sentence with greater difficulty if the word after because is different from the specific word they expected (i.e. different from the bias-consistent pronoun), or (b) participants process the rest of the sentence with greater difficulty if pronoun after because requires them to retrieve an antecedent which is less focussed than the antecedent of the bias-consistent pronoun. The wider question of whether the relative ease of processing bias-consistent pronouns should be attributed to the prediction of a bias-consistent pronoun or to the integration of this pronoun into the unfolding discourse remained unanswered.

\section{Investigating the word-specific prediction account of the implicit- causality effect}

In order to address this issue, the present investigation built upon Koornneef and Van Berkum's (2006) investigation by adding a third possible continuation to the implicit-causality sentences. The original research was done using the two continuation types, namely 'because + congruent pronoun' and 'because + incongruent pronoun'. The present experiment added the third alternative continuation 'because + there'. This continuation was neutral with regards to the bias of the verb and was not an anaphoric expression. As such, any differences in processing sentences containing there could not be due to the greater accessibility of one of the antecedents.

According to Koornneef and Van Berkum's (2006) speculation, the processing of there after an implicit-causality bias should be as problematic as the processing of a bias-inconsistent pronoun. However, according to the accessibility hypothesis, only the processing of a bias-inconsistent pronoun should prove difficult. The present eyetracking investigation, detailed below, aimed to disentangle these two possible accounts of the implicit-causality effect. 


\section{Experiment}

As mentioned above, the present experiment builds upon Koornneef and Van Berkum's (2006) study. In the original study, participants read sentences under two conditions. Sentences were of the type 'Name1 - verb - name2 - because critical...', where verb represents an implicit-causality verb and the critical element a bias-consistent pronoun in a consistent condition or a bias-inconsistent pronoun in inconsistent condition. In order both to replicate Koornneef and Van Berkum's (2006) data and to challenge their suggestion that any word which was not the predicted pronoun would cause processing difficulties, it was necessary to add an alternative continuation after because, thus adding a third condition to the experiment. There was chosen as the third alternative critical word because it could not, within this type of sentences, be construed as an anaphoric expression. The three initial conditions for the present experiment were therefore consistent, inconsistent, and there. In these three conditions, the critical elements, namely a bias-consistent pronoun, a bias-inconsistent pronoun and the word there were read 'post-bias', in other words, after the main verb of the sentence which introduced the implicit-causality bias. For greater clarity, these three first conditions were therefore respectively named Consistent-Post (ConsistentPost), Inconsistent-Post (I-Po), and There-Post (Th-Po).

Because of the lack of direct comparability between there and he or there and she, baseline sentences were added to the design. These sentences enabled the analysis of any interaction effects between the place in which the critical element occurred in the sentence (pre- or post-bias) and the nature of the critical element (pronoun or there). This analysis was carried out to detect whether any differences in processing difficulty between sentences containing there and sentences containing a bias-consistent pronoun should be attributed to the nature of the critical element itself or to the presence of an implicit-causality context which had affected the processing of there differently to the way in which it had affected the processing of a biasconsistent pronoun. The baseline sentences were created by placing the becauseclause before the implicit causality verb, resulting in the construction 'Because critical - [...], name1 - verb - name2' in which the critical word was either a pronoun or there. The pronouns in the first clause could, in these conditions, not be considered consistent or inconsistent with an implicit-causality context, since they were processed by the reader before the context was established. These two extra conditions were therefore named Pronoun-Pre (Pro-Pre) and There-Pre (Th-Pre). 
The present experiment therefore presented a total of five conditions which involved two critical manipulations. The first one was the nature of the word after because, namely a bias-consistent pronoun, a bias-inconsistent pronoun or there. The second one was whether this critical element was read before or after an implicitcausality bias had been read. As in Koornneef and Van Berkum's (2006) second experiment, eye-tracking was used to detect any change in processing difficulty between the conditions. The collected data was analysed in terms of first pass durations, regression path durations, second pass reading times, regressions in and regressions out. These measures were chosen in order enable the investigation both of the time-scale within which the processing difficulties may occur and of the regressive movements which may occur following the reading of a bias-inconsistent pronoun. However, the primary aim of this data collection was the investigation of the veracity of Koornneef and Van Berkum's (2006) speculation of a word-specific prediction of a bias-consistent pronoun as an explanation for the implicit-causality effect.

\section{Method}

\section{Participants}

The eye-tracking experiment was carried out on a sample of 50 participants (16 males), aged 16 to 43 (mean age 22.4), recruited via posters, Edinburgh University mailing lists and the University student employment agency SAG All participants were native speakers of British English with no diagnosed reading or learning disability.

\section{Materials}

Because of the necessity of selecting verbs with a strong implicit-causality bias and because of the addition of a third type of sentence continuation which had not been studied in previous implicit-causality investigations, a pretest was carried out to guide the selection of the verbs to be used in the main study's experimental items.

For the purposes of the pretest, a sample of 50 participants (21 males) aged 16 to 32 (mean age, 22.54) were recruited online. All participants were native speakers of British English with no diagnosed reading or learning disability. 
The pre-test was in the form of a sentence completion task. Participants were sent one of four sets of sentences to complete, pretesting a total of 120 verbs. This list of 120 verbs, consisting of verbs used in previous verb-bias investigations (Caramazza et al, 1977; Long, \& De Ley, 2000; Stewart, Pickering, \& Sanford, 2000; Koornneef, \& van Berkum, 2006) and their synonyms, was randomly divided into two lists of 60 verbs, each containing 30 verbs categorised as 'NP1-biased verbs' in previous investigations, and 30 verbs categorised as 'NP2-bias verbs' in previous investigations. NP1-bias verbs, such as amuse typically invite an explanation revolving around the first of the two names mentioned either side of the verb (i.e. John in John amused Mary), whereas NP2-bias verbs, such as blame, typically invite an explanation revolving around the second name (i.e. Mary in John blamed Mary). These two sets of 60 verbs were also presented to participants in two different randomised orders. In Koornneef and Van Berkum's (2006) pretest, participants were presented with sentences such as 'John disappointed Paul because he...' (p 449) and asked to circle which of the two possible antecedents of he this pronoun referred to. However, it was decided in the present pre-test to give participants a sentence completion task in which they were asked to complete sentences of the form 'Jonathan disappointed Jennifer because... '. This decision was based on the fact that some verbs may more readily invite a continuation concerning one antecedent over another without necessarily inviting participants to predict a continuation with a pronoun (i.e. Matthew admired Hannah because of amazing musicality). This method therefore enabled the selection of verbs based not only on their bias towards the mention of one of the two antecedents, but also based on their propensity to be followed by a pronoun referring to either of the two antecedents. Although the order in which the verbs occurred in the sentence-completion task was randomised between the two tests containing the same set of verbs, the order of names of the two characters mentioned in the first clause of the sentence to be completed was kept identical. This manipulation aimed to ensure that no verb-bias effects could be attributed to either the name or gender of the antecedent toward which the bias pointed.

Sentence continuations were analysed on a frequency basis, categorising responses 'NP1 pronoun continuation', 'NP2 pronoun continuation', 'other', and 'missing data'. The percentage of each type of continuation for the 120 pretested verbs was is presented in Table 2.1. 
The average percentages of types of continuations were as follows: preferred pronoun $(87.12 \%)$, non-preferred pronoun $(6.24 \%)$, other $(6.40 \%)$, missing data $(0.24 \%)$. Only verbs which had been consistently followed over $70 \%$ of the time by one of the two possible pronouns were selected for the construction of the eyetracking experimental items, with a maximum of 25 verbs per verb-bias. Though this pretest largely confirmed the previous categorisations of the featured verbs (Caramazza et al, 1977; Long \& De Ley, 2000; Stewart, Pickering, \& Sanford, 2000; Koornneef \& van Berkum, 2006), the possibility of a continuation which was not a personal pronoun referring to one of the names from the first clause of the sentence enabled a more precise representation of the probabilities of the different sentence continuations.

Following the procedure used by Koornneef and Van Berkum (2006), the first set of post-bias experimental items for the bias-consistent, bias-inconsistent and there conditions were, as previously mentioned, of the form 'Name1 - verb - name 2 because - critical...'. When the critical element was a pronoun, the gender of this pronoun was varied between sets of experimental items, but was kept the same for every given verb. The order of the two names either side of the main verb was therefore manipulated between conditions to enable this cross-condition consistency of the pronoun in the critical region. As in Koornneef and Van Berkum's (2006) study, the five words following the pronoun were kept identical across all three conditions, to accommodate for any spillover effects, but the ends of the sentences were manipulated between conditions to allow for coherent sentences.

For the baseline pre-bias items, the because-clause was placed at the beginning of the sentence rather than after the main clause. The order of the names was also manipulated in these sentences when the because-clause included a pronoun. It was decided that, to ease the reading of these sentences, the pronoun should be of the gender of the first name in the main clause (i.e. 'Because he..., John') regardless of the bias of the verb. This measure resulted in an inconsistency between NP1-bias verbs and NP2-bias verbs, in terms of which of the two because-clauses with a 
Table 2.1. Pretest results - frequency of sentence continuation types per verb.

\begin{tabular}{|c|c|c|c|c|}
\hline Verb & NP1 (\%) & NP2 (\%) & Other (\%) & Missing (\%) \\
\hline \multicolumn{5}{|l|}{ NPl-biased verbs } \\
\hline Lie & 96 & 0 & 4 & 0 \\
\hline Upset & 92 & 0 & 8 & 0 \\
\hline Confess & 92 & 0 & 8 & 0 \\
\hline Telephone & 92 & 0 & 8 & 0 \\
\hline Annoy & 92 & 4 & 4 & 0 \\
\hline Apologise & 92 & 4 & 4 & 0 \\
\hline Call & 92 & 8 & 0 & 0 \\
\hline Bore & 88 & 0 & 12 & 0 \\
\hline Mislead & 88 & 4 & 8 & 0 \\
\hline Charm & 88 & 4 & 8 & 0 \\
\hline Amuse & 88 & 4 & 8 & 0 \\
\hline Enrage & 88 & 4 & 8 & 0 \\
\hline Exasperate & 88 & 12 & 0 & 0 \\
\hline Anger & 88 & 12 & 0 & 0 \\
\hline Scare & 84 & 0 & 16 & 0 \\
\hline Peeve & 84 & 4 & 8 & 0 \\
\hline Intimidate & 80 & 4 & 16 & 0 \\
\hline Alarm & 80 & 12 & 8 & 0 \\
\hline Deceive & 80 & 12 & 8 & 0 \\
\hline Infuriate & 80 & 16 & 4 & 0 \\
\hline Disappoint & 80 & 20 & 0 & 0 \\
\hline Irritate & 76 & 8 & 16 & 0 \\
\hline Follow & 76 & 24 & 0 & 0 \\
\hline Worry & 76 & 24 & 0 & 0 \\
\hline Captivate & 72 & 8 & 16 & 4 \\
\hline \multicolumn{5}{|l|}{ NP2-biased verbs } \\
\hline Sack & 0 & 100 & 0 & 0 \\
\hline Think highly of & 0 & 100 & 0 & 0 \\
\hline Fire & 0 & 100 & 0 & 0 \\
\hline Respect & 0 & 96 & 4 & 0 \\
\hline Admire & 4 & 96 & 0 & 0 \\
\hline Scold & 4 & 96 & 4 & 0 \\
\hline Be fond of & 0 & 92 & 8 & 0 \\
\hline Detest & 4 & 92 & 4 & 0 \\
\hline Be scared of & 4 & 92 & 4 & 0 \\
\hline Be jealous of & 8 & 92 & 0 & 0 \\
\hline Hate & 0 & 88 & 12 & 0 \\
\hline Resent & 4 & 88 & 8 & 0 \\
\hline Adore & 8 & 88 & 4 & 0 \\
\hline Thank & 8 & 88 & 4 & 0 \\
\hline Like & 8 & 88 & 4 & 0 \\
\hline Be terrified of & 12 & 88 & 0 & 0 \\
\hline Be grateful to & 0 & 84 & 16 & 0 \\
\hline Notice & 8 & 84 & 8 & 0 \\
\hline Envy & 8 & 84 & 8 & 0 \\
\hline Disapprove of & 8 & 84 & 8 & 0 \\
\hline Approve of & 12 & 84 & 4 & 0 \\
\hline Congratulate & 0 & 80 & 16 & 4 \\
\hline Pay tribute to & 8 & 80 & 8 & 4 \\
\hline Loathe & 8 & 80 & 12 & 0 \\
\hline Praise & 8 & 80 & 12 & 0 \\
\hline
\end{tabular}

pronoun as a subject from the previous set of items would be used. However, since the five words following the critical region were kept identical across conditions and 
since the only first-pass measures in the pronoun and the five words following it were analysed in the baseline conditions, this inconsistency was of no consequence for the present study. In order to clarify these descriptions of the experimental items, example sentences of each condition for one NP1-bias verb and one NP2-bias verb are presented in Figure 2.1. The full list of experimental items is presented as an appendix to the present report.

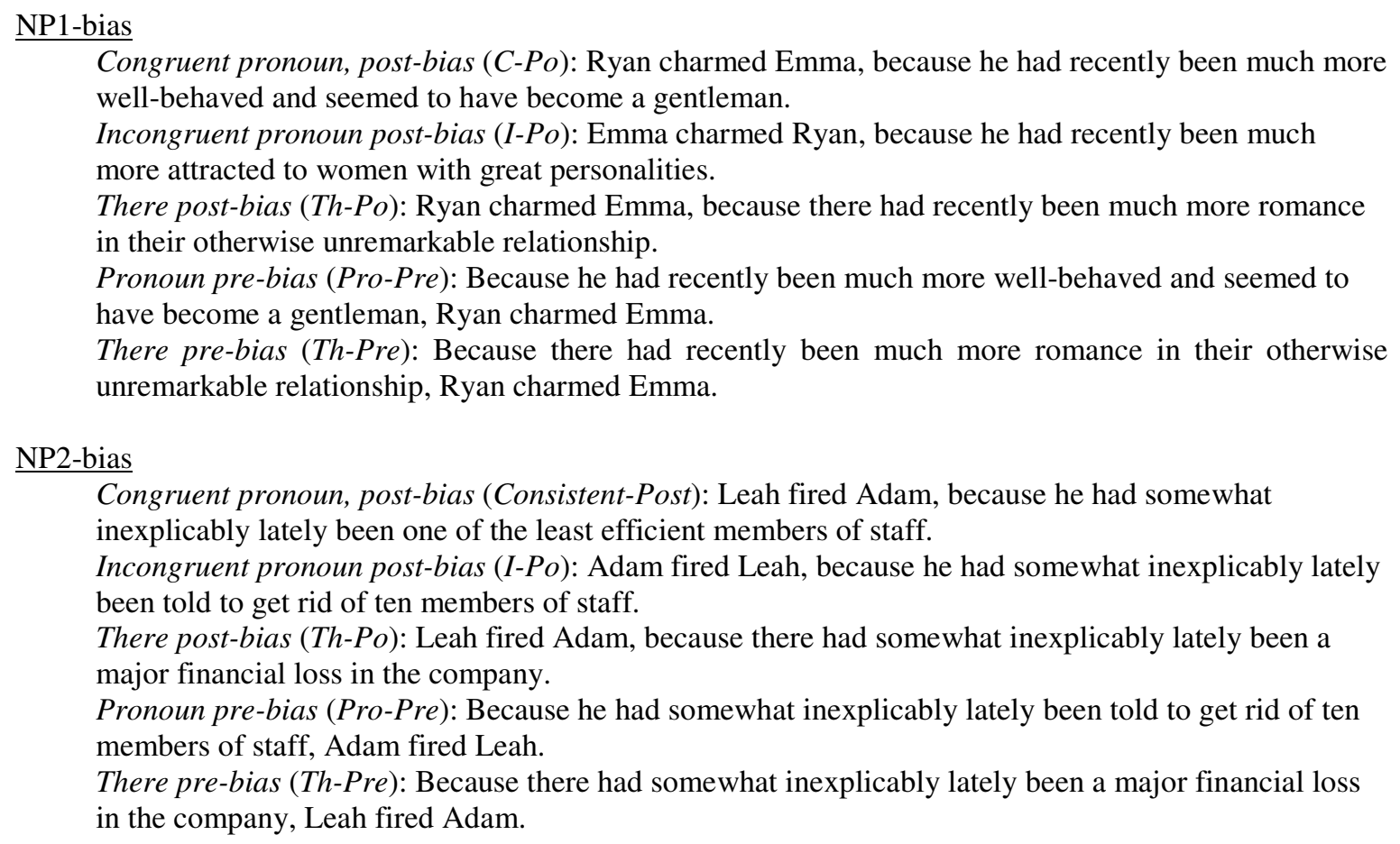

Figure 2.1. Example sentences per condition and verb bias.

To disguise the aims of the experiment, filler sentences, which bore either a close resemblance (i.e. 'The police arrested the chef because his recipe of asparagus and rhubarb crumble turned out to be a deadly poison'), a loose resemblance (i.e. 'Bill was concerned because he just realised he had his wife's socks on') or no resemblance at all (i.e. 'Charlotte was ecstatic that her iguana could sing') to the experimental items described above, were added with a ratio of two fillers for every experimental item. In order to ensure that participants were engaging with the materials, one sentence in five was followed by a simple question (i.e. 'Who could sing?'), the answer of which participants were to select between two options displayed below the question on the same screen, one towards the left ('Charlotte'), one towards the right ('The iguana'). Half of the correct answers were on the right of the screen and half were on the left. The 250 experimental items were divided into five lists, so that participants only saw one of the five items constructed from each 
implicit-causality verb. The fillers were kept identical across lists. Finally, to control for any order effects, the order in which the sentences were displayed was randomised, interleaving experimental items and fillers.

\section{Design}

The present investigation required a two-fold design, involving a 1x3 ANOVA and a 2x2 ANOVA. The factors and levels for each of these analyses are detailed below. The overall design was within-subjects, and in both parts of the design, the dependent variable was the amount of difficulty involved in processing each experimental item, portrayed in delays or regressive eye movements.

The purpose of the $1 \times 3$ ANOVA, was to compare processing difficulty across the first three conditions detailed above, namely Consistent-Post, Inconsistent-Post, and There-Post, where the critical region is read after the implicit-causality verb. The three levels of the within-participants factor 'word' were bias-consistent pronoun, bias-inconsistent pronoun, and there. Firstly, by comparing conditions ConsistentPost and Inconsistent-Post the 1x3 ANOVA aimed to establish whether Koornneef and Van Berkum's (2006) observation of mid-sentence delays in the processing of sentences containing a bias-inconsistent pronoun was replicated in the present study. The second aim of the 1x3 ANOVA was to carry out a naïve investigation of any differences in eye-tracking data between sentences containing there and sentences containing a bias-consistent pronoun. However, the differences in length and in semantics between the word there and the two personal pronouns used in this study were likely to affect the duration and frequency of fixations on the critical region (Morris, 2006). This in turn could lead to differences in landing sites and spillover effect in subsequent regions between conditions, presenting potential confounds in the study of the effect of implicit-causality context on sentence processing.

A $2 \times 2$ ANOVA design was therefore applied to the data collected in conditions Consistent-Post, There-Post, Pronoun-Pre and There-Pre. The two, twolevel, within-participants, factors were context (pre- or post- bias) and word (pronoun or there). This analysis was carried out on first-pass measures only, since it was not possible to control the level of implicit-causality context seen by participants prior to regressions, to further inform any significant differences between processing difficulties seen in the conditions Consistent-Post and There-Post in the 1x3 ANOVA. If Koornneef and Van Berkum's (2006) speculation is correct, a significant word $\mathrm{x}$ 
context interaction should be found, since the difficulty involved in processing there should be higher in the post-bias context than in the pre-bias context whereas processing difficulty for the bias-consistent pronoun should not be more difficult in the post-bias context than in the pre-bias context. However, should the differences between Consistent-Post and There-Post be due only to processing differences between the word there and the pronoun, only a significant main effect of word would be found since the implicit-causality context would not affect the processing of there differently to the way it would affect the processing of the bias-consistent pronoun.

\section{Procedure}

In the present study, participants were asked to silently read sentences which were presented on a 21 -inch CRT display screen with a $120 \mathrm{~Hz}$ refresh rate, while the eye-tracking device Eyelink 1000 recorded their eye-movements. This newly developed video-based eye-tracker offers a $1 \mathrm{kHz}$ sampling rate. The device was used in what its creators refer to as a 'tower configuration' (see Figure 2.2). In order to optimise the eye-tracking range, this device uses an infrared mirror which is transparent in visible light but is reflective to the infrared light used to illuminate the participant's eye. The padded chin-rest and forehead-rest enable a comfortable use of the eye-tracker while restricting head-movement. The focal imaging technology used on this device allows for $+/-25 \mathrm{~mm}$ of vertical or horizontal head movement without disrupting the collection of data.

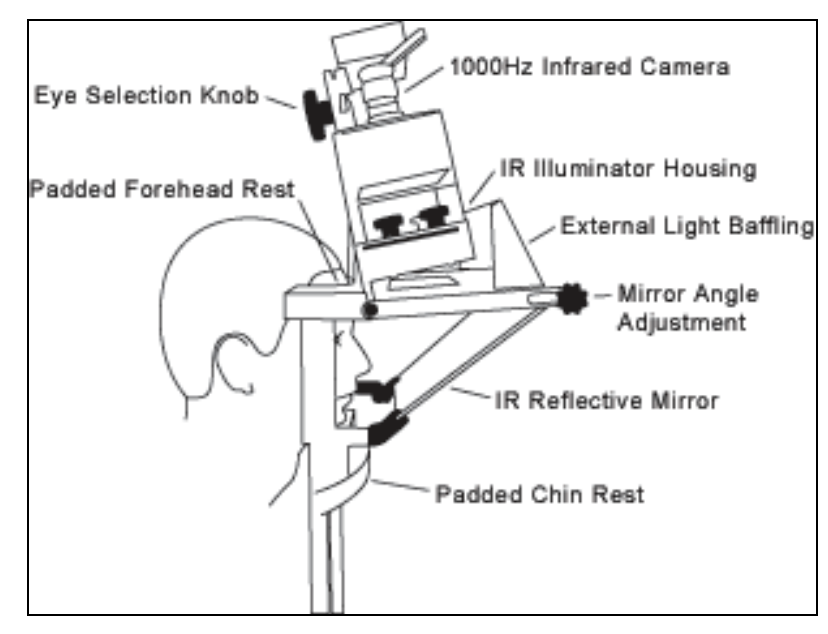

Figure 2.2. Eyelink 1000 Tower Mont setup. Courtesy of SR Research. (www.eyelinkinfo.com/fixed main.php)

The screen was situated $81 \mathrm{~cm}$ away from the eye-tracker. Sentences were displayed as a whole in Times New Roman 18p on the screen with a maximum of two 
lines per sentence. The cubicle in which the experiment took place was also equipped with a game-pad, to record participants' responses to questions and to enable them to move to the next sentence. Before setting up the eye-tracker, participants were instructed on how to use the game-pad throughout the experiment. The X-button was used to move to the next sentence, and the Left and Right triggers, to answer the questions. They were also given instructions as to the eye-gaze trigger procedure. Before each sentence appeared, participants were required to fixate on a black box. This box was situated at the same place as where the first few letters of each sentence would appear on the screen and acted as a gaze trigger. This procedure enabled the experimenter to test the calibration of the tracker at onset of every sentence.

During the calibration procedure, participants were asked to fixate on 9 dots which appeared sequentially in a random order in the four corners of the screen, the middle of each side of the screen and the centre of the screen. Following a successful calibration, participants proceeded to complete three practice trials, two of which were followed by a question, to ensure that the instructions had been correctly understood. After the practice session and any subsequent clarifications of the participants' task, the eye-tracker calibrated once more and the experimental trials began. Once participants had reached the midway point of the experiment, the experimenter used the next filler to offer participants a short break. After the break, the calibration procedure was repeated before resuming the experiment. The eye-tracker was also recalibrated if the eye-gaze trigger procedure failed on any given sentence. Each complete session lasted approximately 30 minutes.

\section{Results}

In view of the complex nature of data collected in eye-tracking studies, the results section of the present investigation will be divided into different measures. The reported measures are first pass reading times (the sum of all fixations in a region from entering to leaving that region), regression path durations (the sum of all fixations in a region from first entering the region, including any regressions that are made, until moving to the right of the region), second pass reading times (the sum of all fixations in a region following the initial first pass reading time), first-pass regressions out (the percentage of regressions out of a region after entering it for the first time) and regressions in (the percentage of regressions in to a region from the right after having left that region to the right). Since Koornneef and Van Berkum 
(2006) did not find a significant interaction between verb-bias (NP1-bias or NP2-bias) and type of continuation (bias-consistent pronoun or bias-inconsistent pronoun), it was not deemed necessary to analyse NP1-bias verbs separately from NP2-bias verbs.

Each sentence was divided into 11 regions as detailed below in Table 3.0. Since the end of the because-clause was modified between conditions to allow for a coherent sentence continuation, this region was not comparable between conditions and therefore does not feature in the present analysis. Because of the use of baseline sentences, the order in which these regions were read varied between the first three conditions and the last two conditions of the experiment. The regions are therefore referred to with verbal labels rather than numbers. When regions $c r+1$ to $c r+5$ were combined in the present analysis, the resulting region is referred to as the combined region.

Table 3.0 Regions used per condition in the analysis of eye-tracking data.

\begin{tabular}{|c|c|c|c|c|c|c|c|c|c|c|}
\hline \multirow[b]{3}{*}{$C-P o$} & \multicolumn{10}{|c|}{ Region } \\
\hline & name $_{1}$ & verb & name $_{2}$ & because & critical & $\mathrm{cr}+1$ & $\mathrm{cr}+2$ & $\mathrm{cr}+3$ & $\mathrm{cr}+4$ & cr+5 \\
\hline & Leah & fired & Adam, & because & he & had & somewhat & inexplicably & lately & been \\
\hline$I-P o$ & Adam & fired & Leah, & because & he & had & somewhat & inexplicably & lately & been \\
\hline$T h-P o$ & Leah & fired & Adam, & because & there & had & somewhat & inexplicably & lately & been \\
\hline Pro-Pre & ...Adam & fired & Leah. & Because & he & had & somewhat & inexplicably & lately & been \\
\hline Th-Pre & ...Leah & fired & Adam. & Because & he & had & somewhat & inexplicably & lately & been \\
\hline
\end{tabular}

Before any analysis took place, certain measures were taken to ensure the reliability of the collected data. For the analysis of the word-long regions detailed above, any fixations of less than $80 \mathrm{~ms}$ in any given region were excluded from the data, as were fixations exceeding $1200 \mathrm{~ms}$. When the five regions after the critical region were combined, fixations of less than $80 \mathrm{~ms}$ were also excluded, but, because the combined region contained five regions from the previous analysis, the maximum fixation duration was changed to $6000 \mathrm{~ms}$. Since this procedure resulted in the loss of some data, degrees of freedom vary across regions for one type of analysis. The probabilities reported for each $F$-value were calculated using the adjusted degrees of freedom, while the summary tables for each analysis present the theoretical degrees of freedom for each analysis. The probability values were also adjusted when sphericity assumptions were not met, reporting the outcome of a Greenhouse-Geisser correction analysis. 
For each eye-tracking measure, a 1x3 ANOVA was carried out on both the F1 data (by-participants analysis) and the F2 data (by-items analysis). As mentioned previously, this initial analysis aimed to establish the significance of any differences in reading patterns between across the first three 'post-bias' conditions of the experiment. Any significant main effects of condition detected in 1x3 ANOVAs were followed up by a Planned Comparisons analysis on the F1 data, using the method of Least Significant Difference (LSD) at a 5\% probability level.

In cases where the $1 \times 3$ ANOVA displayed significant differences between conditions, a $2 \times 2$ ANOVA was also carried out to further compare conditions Consistent-Post, Pronoun-Pre, There-Post and There-Pre. As explained in the design section, this measure was made necessary by the lack of comparability between there and he or there and she and aimed to establish whether the differences between reading patterns in conditions Consistent-Post and There-Post should be attributed to a main effect of word or to the presence of an implicit-causality context.

\section{First pass reading time}

Mean first pass reading times are displayed in Table 3.1 and Figure 3.1. Because of the nature of first pass reading times, only the regions in the becauseclause were included in the analysis, since those were the only regions to be potentially affected by the presence of an implicit-causality bias. Table 3.1 also presents the outcome of the 1x3 ANOVA detailed below.

Table 3.1. First pass reading time analysis for regions because to $c r+5$.

\begin{tabular}{|c|c|c|c|c|c|c|c|}
\hline & \multicolumn{7}{|c|}{ Region } \\
\hline & because & critical & cr+1 & cr+2 & cr+3 & cr+4 & $\mathbf{c r}+5$ \\
\hline & because & he / there & had & somewhat & inexplicably & lately & been \\
\hline \multicolumn{8}{|c|}{ Mean first pass reading time (in $\mathrm{ms}$ ) for all five conditions (F1) } \\
\hline C-Po & 244 & 236 & 248 & 266 & 246 & 259 & 251 \\
\hline$I-P o$ & 245 & 226 & 262 & 269 & 258 & 252 & 261 \\
\hline Th-Po & 250 & 226 & 243 & 254 & 253 & 244 & 250 \\
\hline Pro-Pre & 190 & 218 & 243 & 245 & 251 & 244 & 249 \\
\hline Th-Pre & 185 & 220 & 222 & 238 & 243 & 243 & 254 \\
\hline \multicolumn{8}{|c|}{$1 \times 3$ ANOVA for conditions 1 to 3} \\
\hline$F 1(2,98)$ & $<1$ & $<1$ & 3.09 & 1.55 & 1.29 & 1.05 & 1.09 \\
\hline$p$ & 0.70 & 0.51 & $0.05^{*}$ & 0.22 & 0.28 & 0.35 & 0.34 \\
\hline$F 2(2,98)$ & $<1$ & 1.22 & 3.05 & $<1$ & $<1$ & $<1$ & 1.13 \\
\hline$p$ & 0.49 & 0.30 & $0.05 *$ & 0.85 & 0.41 & 0.84 & 0.33 \\
\hline
\end{tabular}




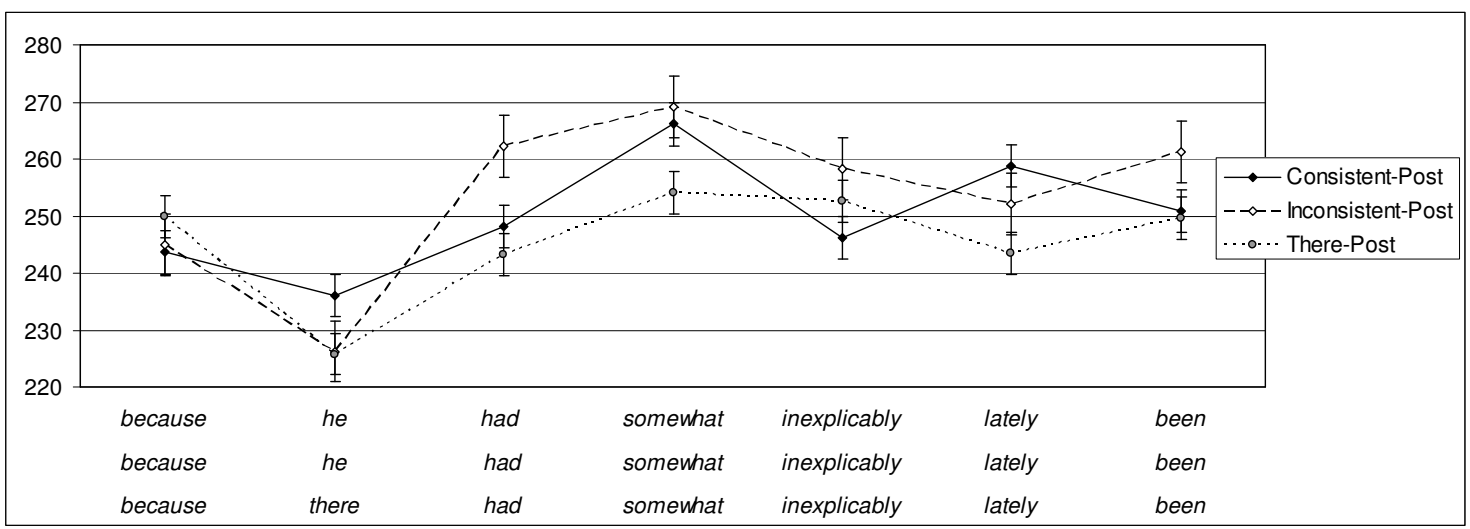

Figure 3.1. First pass reading time means (and standard errors) for regions because to $c r+5$.

As seen in Table 3.1, the 1x3 ANOVA revealed statistically significant differences between the three post-bias conditions for region $c r+1(F 1(2,98)=3.09$, $p=0.05, F 2(2,98)=3.05, \mathrm{p}=0.05)$. The planned comparisons analysis showed that these differences were significant both between conditions Consistent-Post and Inconsistent-Post $(\mathrm{MD}=-14.16, p=0.04)$ and between conditions Inconsistent-Post and There-Post $(\mathrm{MD}=19.08, p=0.04)$. Thus, it appears that, relative the ConsistentPost condition as well as to the There-Post condition, the presence of a biasinconsistent pronoun resulted in longer first pass fixations in regions following the critical region.

A 2x2 ANOVA was carried out in order to further investigate the difference in reading times between conditions Consistent-Post and There-Post. The means reported above show that $c r+1$ was read slightly faster in sentences containing there than in sentences containing a bias-consistent pronoun (respectively $248 \mathrm{~ms}$ and $243 \mathrm{~ms}$ ) in the post-bias conditions. However, a similar pattern was observed in the pre-bias conditions where reading times for $\mathrm{cr}+1$ in sentences containing a pronoun and sentences containing there were respectively $243 \mathrm{~ms}$ and $222 \mathrm{~ms}$. The results of the $2 \times 2$ ANOVA did not show any significant word $x$ context interaction effects ( $F 1$ $(1,49)<1, p=0.86 ; F 2(1,48)=1.71, p=0.20)$ but did show a significant main effect of $\operatorname{word}(F 1(1,49)=7.99, p=0.01 ; F 2(1,48)=6.49, p=0.01)$. These results indicate that region $\mathrm{cr}+1$ was read slightly faster in sentences containing there than in sentences containing a bias-consistent pronoun, irrespective of presence or absence of an implicit-causality context.

When combining regions $c r+1$ to $c r+5$, the mean first pass fixation times on the combined regions for conditions Consistent-Post, Inconsistent-Post and There- 
Post were respectively $838 \mathrm{~ms}, 841 \mathrm{~ms}$ and $803 \mathrm{~ms}$. Despite these discrepancies, the results of the 1x3 ANOVA showed no significant main effect of condition $(F 1(2,98)$ $=1.12, p=0.33 ; F 2(2,98)<1, p=0.45)$. Consequently, though a significant effect was observed early in the regions following the critical region, first-pass reading times showed no significant difference between conditions when the five regions after the critical region were combined.

\section{Regression Path Duration Analysis}

The outcome of the analysis of regression path durations is presented below. Once more, because of the first-pass nature of these regression path durations, Table 3.2 and Figure 3.2 only present the mean durations for the regions in the becauseclauses. The results of the 1x3 ANOVA are also presented in Table 3.2.

Comparing regression path durations in the three post-bias conditions, the $1 \times 3$ ANOVA revealed significantly different means between conditions on region $c r+3$ $(F 1(2,98)=7.07, p=0.001 ; F 2(2,98)=6.52, p=0.01)$. The planned comparison analysis confirmed the trend suggested by the means presented in the table and figure above, namely that regression path durations were lower in the Consistent-Post condition than in both the Inconsistent-Post condition (MD = -32.12, $p=0.02$ ) and the There-Post condition (MD = -61.68, $p=0.001)$.

Table 3.2. Regression Path Duration analysis for regions because to $c r+5$.

\begin{tabular}{|c|c|c|c|c|c|c|c|}
\hline & \multicolumn{7}{|c|}{ Region } \\
\hline & because & critical & cr+1 & cr+2 & $\mathbf{c r}+3$ & cr+4 & $\mathbf{c r}+5$ \\
\hline & because & he / there & had & somewhat & inexplicably & lately & been \\
\hline \multicolumn{8}{|c|}{ Mean regression path durations (in $\mathrm{ms}$ ) for all five conditions (F1) } \\
\hline C-Po & 288 & 280 & 281 & 326 & 293 & 326 & 353 \\
\hline$I-P o$ & 285 & 257 & 293 & 351 & 325 & 312 & 355 \\
\hline$T h-P o$ & 278 & 265 & 301 & 339 & 355 & 300 & 341 \\
\hline Pro-Pre & 190 & 237 & 273 & 322 & 299 & 336 & 340 \\
\hline Th-Pre & 185 & 233 & 263 & 329 & 342 & 323 & 332 \\
\hline \multicolumn{8}{|c|}{ 1x3 ANOVA for conditions 1 to 3} \\
\hline$F 1(2,98)$ & $<1$ & $<1$ & $<1$ & 1.19 & $7.07 * * *$ & $<1$ & $<1$ \\
\hline$p$ & 0.77 & 0.54 & 0.44 & 0.30 & $0.001 * * *$ & 0.50 & 0.85 \\
\hline$F 2(2,98)$ & $<1$ & $<1$ & $<1$ & $<1$ & $6.52 * *$ & $<1$ & 1.11 \\
\hline$p$ & 0.59 & 0.67 & 0.67 & 0.60 & $0.01 * *$ & 0.44 & 0.34 \\
\hline
\end{tabular}




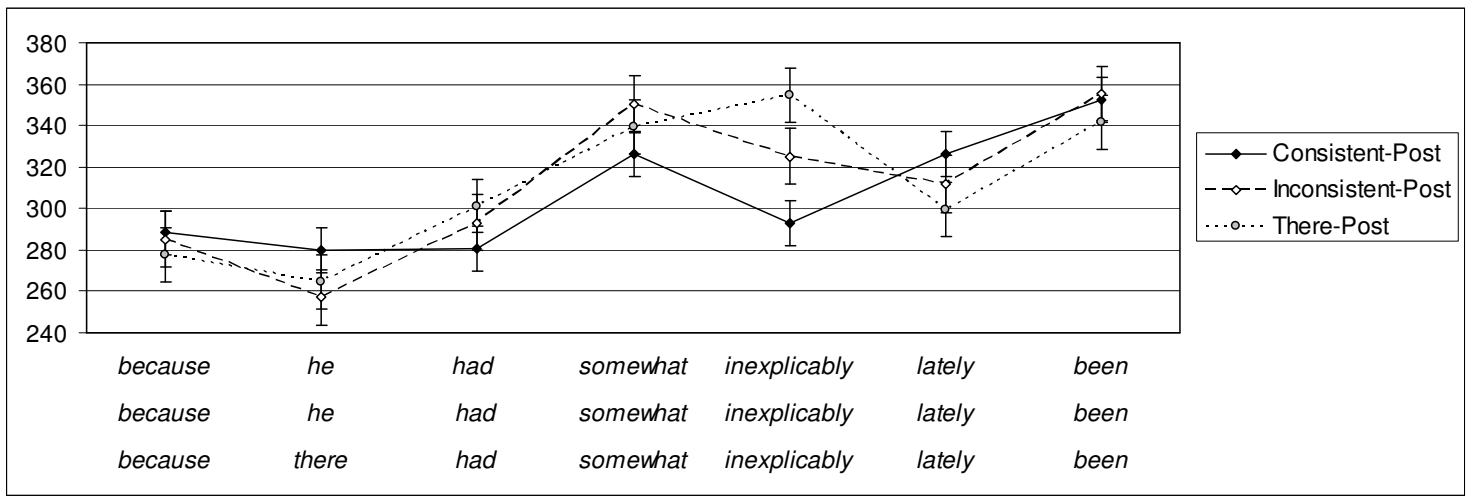

Figure 3.2. Regression path duration analysis.

Though regression path durations on region $c r+3$ was $62 \mathrm{~ms}$ longer in condition There-Post than in condition Consistent-Post, a similar pattern was observed on this region in the pre-bias conditions, where regression path durations were on average 53ms longer in condition There-Pre than in condition Pronoun-Pre. When these four conditions were examined in a 2x2 ANOVA, only a main effect of word was found $(F 1(1,49)=9.60, p=0.003 ; F 2(1,49)=11.44, p=0.001)$. Since no significant word $\mathrm{x}$ context interaction was found $(F 1(1,49)<1, p=0.65 ; F 2(1,49)<$ $1, p=0.54)$, it was once more concluded that the differences between sentences containing there and those containing a bias-consistent pronoun in the pre-bias conditions could not be attributed to the presence of an implicit-causality context.

Once more, on combining regions $c r+1$ to $c r+5$, no significant difference between conditions was seen in the $1 \times 3 \operatorname{ANOVA}(F 1(2,98)=1.61, p=0.21 ; F 2$ $(2,98)<1, p=0.51)$, despite the discrepancies observed between mean regression path duration times in the Consistent-Post, Inconsistent-Post and There-Post conditions (respectively $959 \mathrm{~ms}, 1010 \mathrm{~ms}$ and $992 \mathrm{~ms}$ ). This observation is in line with the previously made observation of first-pass reading times, namely that no effect of context is detected in first pass measures when the regions following the critical element in the sentence are considered as a whole.

\section{Second pass reading time}

The data was also analysed in terms of second pass reading times. Once more, the descriptive data as well as the 1x3 ANOVA outcomes are presented in Table 3.3 and Figure 3.3. Since the second pass reading times on regions prior to the critical region were potentially informative of the cognitive patterns underlying the previously reported slower reading of regions following the critical region, this third data analysis included regions name1 to name2. In this analysis, the sentence-initial 
because-clause in the baseline sentences no reliably reflected the processing of these words in the absence of an implicit-causality context, since participants could have returned to the because-clause after having read the implicit-causality verb. No 2x2 ANOVA was therefore carried out within this analysis.

Table 3.3. Second pass reading times.

\begin{tabular}{|c|c|c|c|c|c|c|c|c|c|c|}
\hline & \multicolumn{10}{|c|}{ Region } \\
\hline & $\begin{array}{c}\text { name }_{\mathbf{1}} \\
\text { Leah } \\
\text { /Adam } \\
\end{array}$ & $\begin{array}{l}\text { verb } \\
\text { fired }\end{array}$ & $\begin{array}{c}\text { name }_{2} \\
\text { Adam } \\
\text { Leah, }\end{array}$ & $\begin{array}{l}\text { bec. } \\
\text { bec. }\end{array}$ & $\begin{array}{c}\text { Cr. } \\
\text { he } \\
\text { /there } \\
\end{array}$ & $\begin{array}{c}\text { cr+1 } \\
\text { had }\end{array}$ & $\begin{array}{c}\text { cr+2 } \\
\text { s.what }\end{array}$ & $\begin{array}{c}\text { cr+3 } \\
\text { inexpl. }\end{array}$ & $\begin{array}{l}\text { cr+4 } \\
\text { lately }\end{array}$ & $\begin{array}{c}\text { cr+5 } \\
\text { been }\end{array}$ \\
\hline \multicolumn{11}{|c|}{ Mean regression path duration (in $\mathrm{ms}$ ) for all five conditions } \\
\hline C-Po & 188 & 270 & 111 & 57 & 29 & 61 & 84 & 74 & 36 & 58 \\
\hline $\mathrm{I}-\mathrm{Po}$ & 176 & 297 & 150 & 103 & 49 & 82 & 115 & 98 & 53 & 60 \\
\hline Th-Po & 165 & 292 & 119 & 86 & 77 & 90 & 124 & 83 & 51 & 59 \\
\hline Pro-Pre & 127 & 210 & 89 & 77 & 63 & 89 & 103 & 103 & 50 & 68 \\
\hline Th-Pre & 142 & 201 & 89 & 74 & 97 & 98 & 127 & 95 & 57 & 57 \\
\hline \multicolumn{11}{|c|}{ 1x3 ANOVA between conditions 1 to 3} \\
\hline $\begin{array}{l}\text { F1 } \\
(2,98)\end{array}$ & 1.41 & 3.37 & 8.42 & 9.32 & 9.28 & 3.29 & 4.52 & 2.70 & 4.46 & $<1$ \\
\hline $\mathrm{P}$ & 0.25 & $\begin{array}{c}0.05 \\
*\end{array}$ & $\begin{array}{c}0.001 \\
* * *\end{array}$ & $\begin{array}{c}0.001 \\
* * *\end{array}$ & $\begin{array}{c}0.001 \\
* * *\end{array}$ & $\begin{array}{c}0.04 \\
*\end{array}$ & $\begin{array}{c}0.01 \\
*\end{array}$ & 0.07 & $\begin{array}{c}0.02 \\
*\end{array}$ & 0.83 \\
\hline $\begin{array}{l}\mathrm{F} 2 \\
(2,98)\end{array}$ & $<1$ & 1.95 & 5.07 & 6.83 & 5.37 & 2.04 & 2.84 & 2.23 & 3.24 & $<1$ \\
\hline $\mathrm{p}$ & 0.39 & 0.15 & $\begin{array}{c}0.01 \\
* *\end{array}$ & $\begin{array}{c}0.004 \\
* *\end{array}$ & $\begin{array}{c}0.01 \\
* *\end{array}$ & 0.14 & 0.06 & 0.12 & $\begin{array}{c}0.05 \\
*\end{array}$ & 0.85 \\
\hline
\end{tabular}

* Significant at $p<0.05$ level, ${ }^{* *}$ Significant at $p<0.01$ level, $* * *$ Significant at $p<0.001$ level

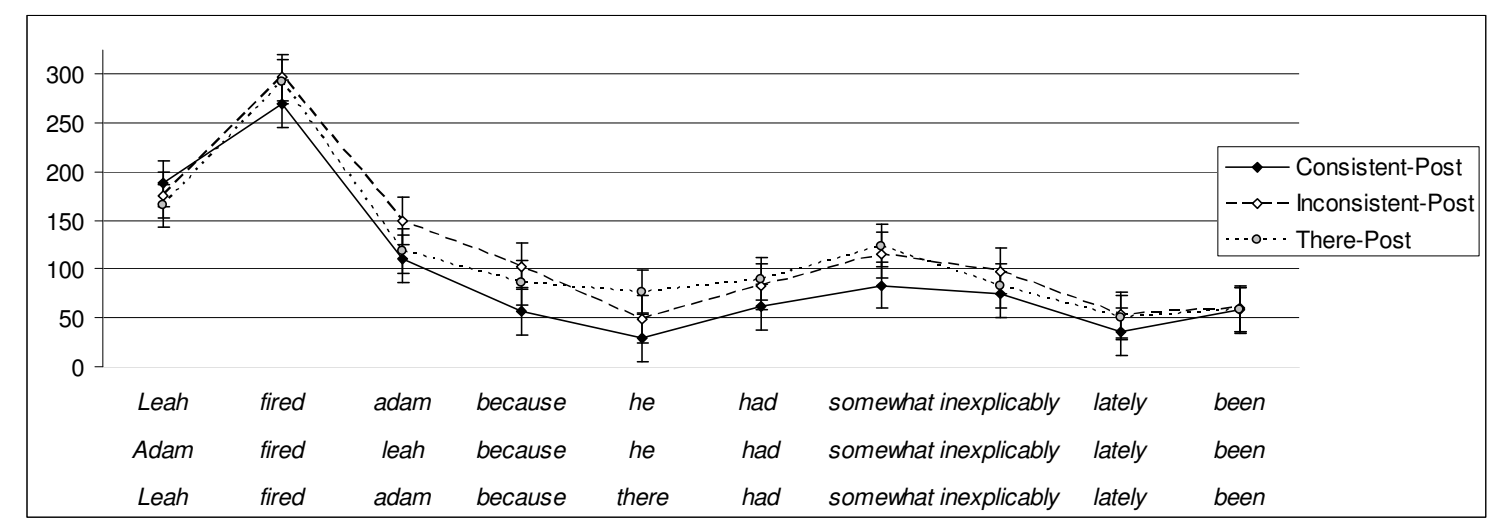

Figure 3.3. Second pass reading times.

As in the analyses presented above, certain words in the regions following the critical region showed significantly different reading patterns across the three postbias conditions. In region $c r+1$, second pass reading times differed significantly between conditions in the by-participants analysis $(F 1(2,98)=3.29, p=0.04)$ but not in the by-items analysis $(F 2(2,98)=2.04, p=0.14)$. The LSD analysis carried out on the Fl data revealed that condition Consistent-Post displayed significantly lower second-pass reading times in this region than both Inconsistent-Post $(\mathrm{MD}=-25.56, p$ 
$=0.01)$ and There-Post $(\mathrm{MD}=-22.22, p=0.05)$ did. Region $c r+2$ followed a similar pattern in the $1 \times 3$ ANOVA $(F 1(2,98)=4.52, p=0.04 ; F 2(2,98)=2.84, p=0.06)$. This time however, only conditions Consistent-Post and Inconsistent-Post were shown to be significantly different in the planned comparisons analysis $(\mathrm{MD}=-35.50$, $p=0.02)$. Region $c r+4$ displayed a significant main effect of condition $(F 1(2,98)=$ $4.46, p=0.02 ; F 2(2,98)=3.24, p=0.05)$. The planned comparisons analysis showed condition Consistent-Post to result in lower second pass reading times than both Inconsistent-Post $(\mathrm{MD}=-25.48, p=0.03)$ and There-Post $(\mathrm{MD}=-23.00, p=0.001)$.

On combining the five regions following the critical region, a significant difference between conditions was seen in the 1x3 ANOVA $(F 1(2,98)=6.16, p=$ $0.003 ; F 2(2.98)=4.46, p=0.01)$. The planned comparison analysis showed that the Consistent-Post condition presented the lower second pass reading times than both the other two conditions, though the difference between Consistent-Post and InconsistentPost (MD $=-113.61, p=0.001)$ reached a higher significance level than the difference between Consistent-Post and There-Post $(\mathrm{MD}=-99.91, p=0.01)$.

The 1x3 ANOVA also demonstrated highly significant differences between mean second pass reading times in the critical region $(F 1(2,98)=9.28, p=0.001 ; F 2$ $(2,98)=5.37, p=0.01)$. However, it transpired in the planned comparisons analysis that condition There-Post presented higher reading times than both Consistent-Post $(\mathrm{MD}=34.22, p=0.02)$ and Inconsistent-Post $(\mathrm{MD}=22.33, p=0.03)$. This trend was therefore attributed to the length of the word there itself rather than to the verb-bias of the sentence, in view of previous literature demonstrating the rarity and brevity of fixations on personal pronouns during discourse processing (Morris, 2006).

Working backwards from the pronoun, mean second pass reading times in the because region showed a significant main effect of condition $(F 1(2,98)=9.32, p=$ $0.0001, F 2(2,98)=6.83, p=0.004)$. In the planned comparisons analysis, it was revealed that second pass reading times were lower in the Consistent-Post condition than in both the Inconsistent-Post $(\mathrm{MD}=-45.45, p=0.0001)$ condition and the TherePost condition (MD $=-30.10, p=0.004)$. However, once more, the difference between Consistent-Post and Inconsistent-Post reached a higher level of significance than the difference between Consistent-Post and There-Post. 
The region of the second name (region 3) also showed significantly different means across conditions $(F 1(2,98)=8.42, p<0.001 ; F 2(2,98)=5.07, p=0.01)$. The difference between conditions Consistent-Post and Inconsistent-Post (MD = -42.24, $p$ $<0.001$ ) presented a much higher significance level that the difference between conditions There-Post and Inconsistent-Post (MD = -35.04, $p=0.01)$. The name in region name2 differed between conditions Consistent-Post and Inconsistent-Post, rendering any direct comparison between these two conditions on this region problematic. However, these names were matched for length and frequency. The observation of highly significant differences between Consistent-Post and Inconsistent-Post should therefore not be totally discarded on the basis of a lack of comparability. These results are futher discussed below in the light of an analysis of regressive eye movements.

Finally, in the verb region, the $1 \times 3$ ANOVA also a significant effect of condition in the by-participants analysis $(F 1(2,98)=3.37, p=0.05)$ but not in the byitems analysis $(F 2(2,98)=1.95, p=0.15)$. The planned comparisons analysis showed that mean second pass reading times differed significantly between conditions Consistent-Post and Inconsistent-Post (MD $=-47.40, p=0.003)$, but not between conditions Consistent-Post and There-Post $(\mathrm{MD}=-22.58, p=0.21)$.

As mentioned above, it was not meaningful to carry out a 2x2 ANOVA on the second pass reading times to establish whether any differences between the Consistent-Post condition and the There-Post condition were due to a main effect of word or to the implicit-causality context affecting the processing of the bias-consistent pronoun differently from the way if affected the processing of there. Regressive eyemovements both out of the regions following the critical region and into the regions in the first clause of the sentence were therefore considered in an attempt to clarify the trends presented above.

\section{First pass regressions out}

The regressions out analysis presented the following mean percentages for the combined region: $9.2 \%$ in Consistent-Post, $13.7 \%$ in Inconsistent-Post and $14.6 \%$ in There-Post. The 1x3 ANOVA revealed significantly different means between the three post-bias conditions $(F 1(2,98)=4.10, p=0.02 ; F 2(2,98)=3.79, p=0.03)$. The planned comparisons analysis revealed that participants carried out significantly less regressions out of the combined region in condition Consistent-Post than in 
condition Inconsistent-Post $(\mathrm{MD}=-4.52, p=0.03)$ and than in condition There-Post $(\mathrm{MD}=-5.36, p=0.01)$. A $2 \times 2$ ANOVA was carried out to further investigate whether the differences between conditions There-Post and Consistent-Post could reliably be attributed to the presence of an implicit-causality context. The mean percentages of first pass regressions out for conditions Pronoun-Pre and There-Pre were respectively $13.7 \%$ and $17.3 \%$, echoing the trend observed between conditions Consistent-Post and There-Post. As in previous measures, no significant interaction effect was found $(F 1(1,49)<1, p=0.52 ; F 2(1,49)<1, p=0.60)$ but a significant main effect of word was found $(F 1(1,49)=10.69, p=0.002 ; F 2(1,49)=7.11, p=0.01)$. Consequently, the significant differences in mean percentages of first pass regressions out from the combined region between conditions Consistent-Post and There-Post were attributed to the nature of the word in the critical region rather than to any different effect of an implicit-causality context. This observation further suggests that the patterns of second-pass reading times observed in regions prior to the critical region reflect an effect of condition rather than an effect of the discrepancies between the two name regions across conditions.

\section{Regressions in}

The percentages of regressions in to the name2 region for conditions Consistent-Post, Inconsistent-Post, and There-Post were respectively 19.5\%, 25.8\% and $22.0 \%$. A significant difference between conditions was seen in the by-subjects analysis $(F 1(2,98)=3.10, p=0.05)$ but not in the by-items analysis $(F 2(2,98)=$ 2.28, $p=0.11$ ). The planned comparisons analysis revealed that there were significantly less regressions into the name 2 region in condition Consistent-Post than in condition Inconsistent-Post $(\mathrm{MD}=-6.38, p=0.02)$ but that no significant difference was seen between conditions Consistent-Post and There-Post (MD = -2.54, $p=0.35$ ). Because of the second-pass nature of regressions in, no $2 \times 2$ ANOVA was carried out. However, the above observation adds further weight to the suggestion above that the patterns observed it the second pass reading times analysis were not due to the differences between region name 2 across conditions but to the differences in the processing patterns resulting from the implicit-causality context, since the regressions-in measure can arguably be considered more independent from the word itself than fixation measures are. 


\section{Summary}

The results reported above show some common trends across the different types of analyses of eye-tracking data.

Firstly, considering the lack of statistical significance of any word $\mathrm{x}$ context interaction effects in the $2 \times 2$ ANOVAs, it was concluded that the presence of an implicit-causality context did not affect the processing of there any differently from the way in which it affected the processing of a bias-consistent pronoun. Moreover, in view of the significant main effect of word observed in the 2x2 ANOVAs, the discrepancies in reading patterns between sentences containing a bias-consistent pronoun and sentences containing there were attributed to differences in the processing of there and personal pronouns, irrespective of the context in which they were seen. Differences between conditions There-Post and Consistent-Post were therefore considered null in this investigation of the implicit-causality effect. Secondly, readers experienced increased processing difficulty on the regions following the critical region when this region featured a bias-inconsistent pronoun. However, on first-pass measures, it appears that this effect is only visible when early regions are considered, suggesting an early effect of context. Thirdly, second pass measures indicated a general increased processing time for sentences featuring a biasinconsistent pronoun compared to sentences featuring a bias-consistent pronoun, as readers spent significantly longer on both the regions following the critical region and those prior to the critical region in the Inconsistent-Post condition. Finally, the observation of regression patterns indicated that the presence of a bias-inconsistent pronoun resulted in a significantly higher percentage of regressions out of the regions following the pronoun and a significantly higher percentage of regressions in to the name2 region.

The implications of these findings for theories surrounding the cognitive underpinnings of the implicit-causality effect are discussed below.

\section{Discussion}

Prompted by Koornneef and Van Berkum's (2006) speculation of a wordspecific prediction account of the implicit-causality effect, the present investigation set out to disentangle two potential explanations for the mid-sentence delays observed in the processing of sentences containing a bias-inconsistent pronoun. The first 
account was a word-specific prediction account, according to which, participants experienced difficulty on processing a bias-inconsistent pronoun because they had previously predicted that the bias-consistent pronoun would be the word following because in sentences such as 'John praise Mary, because...'. Under this theorisation, any word after because which was is the bias-consistent pronoun should cause an increase in processing difficulty. The second account an accessibility account, which suggested that the relative difficulty experienced on reading sentences containing a bias-inconsistent pronoun was due to the higher focus of the antecedents towards whom the verb-bias pointed. The results reported above unequivocally reject the word-specific prediction account, and are discussed in terms of their implications for theories of the cognitive processes underlying the implicit-causality effect.

\section{Implications of the present investigation's findings for the word-specific prediction account of the implicit-causality effect}

First of all, the present investigation was successful in its replication of Koornneef and Van Berkum's (2006) observations concerning the processing of biasinconsistent pronouns. The significantly higher reading times on sentences containing a bias-inconsistent pronoun were reported in both first pass and second pass measures. These effects were most visible in first pass measures when the words following the critical region were analysed separately rather than when the first five words following the pronoun were analysed as a whole. Garnham's (2001) and Stewart et al's (2000) had previously claimed that "verb-based implicit causality is only used during sentence-final clausal integration" (Koornneef \& Van Berkum, 2006, p 454). However, both the data collected during Koornneef and Van Berkum's (2006) study and during the present study show that the effects of implicit causality are most visible when early measures of processing difficulty are used and when the regions immediately following the critical region are considered. Consequently, the present results not only confirm the existence of mid-sentence delays in the processing sentences containing a bias-inconsistent pronoun relative to sentences containing a bias-consistent pronoun, but also lend support to an early-effect account of the use of implicit-causality information in sentence processing.

Secondly, the results of the present study demonstrated that the presence of an implicit-causality context did not affect the processing of sentences containing there any differently from the way it affected the processing of sentences containing a bias- 
consistent pronoun. Though some significant differences were reported between condition There-Post and Consistent-Post, the outcome of a second analysis which compared the differences between the processing of there and of a bias-consistent pronoun with and without an implicit-causality context revealed that these initial differences should be attributed to the different ways in which readers process there and personal pronouns. As a result, the speculation that any word following because in an implicit-causality sentence which was not a bias-consistent pronoun would result in a significant increase in processing difficulty was not supported.

Since the data clearly replicated the delays observed in Koornneef and Van Berkum's (2006) study in sentences containing a bias-inconsistent pronoun, the lack of evidence of processing difficulties in sentences containing there cannot be attributed to a lack of statistical power. Consequently, the results reported above provide strong evidence against Koornneef and Van Berkum's (2006) speculation that the implicit-causality effect could be attributed to participants predicting that the word following because would be a bias-consistent pronoun. Other explanations for the implicit-causality effect (Caramazza et al., 1977) must therefore be sought.

\section{Accessibility and the implicit-causality effect}

According to the linguistic-focus literature, pronominal references are processed faster when their antecedents are focussed than when they are not focussed (Garrod, Greudenthal, \& Boyle, 1994). The situation-model-informed accessibility account of implicit-causality suggests that the antecedent which is most likely to be mentioned in connection with an explanation of the event at hand receives more focus than the other antecedent (Zwaan \& Radvansky, 1998; Arnold, 2001). The delays in processing only sentences containing a bias-inconsistent pronoun observed in the present study provide a first piece of evidence towards this account of the implicitcausality effect. However, the mere observation of delays is in itself not sufficient.

The patterns of regressive eye-movements observed in the present experiment add to the credentials of the accessibility account. Morris and Folk (1998) demonstrated that readers made fewer regressions to and spent less total time on words which were focussed compared to words which were not focussed. Participants both regressed out from the regions following the critical region and regressed in to the region containing the second antecedent significantly more when the critical region was situated post-bias and contained a bias-inconsistent pronoun. This data 
pattern strongly suggests that the explanation for significantly higher regression path durations in 'bias-inconsistent' sentences lies in participants regressing to the region of the second antecedent. This observation in turn leads to the speculation that the principle cause of delays in the processing of implicit-causality sentences which contain a bias-inconsistent pronoun can be attributed to difficulties in integrating the pronoun into a discourse in which its referent has been placed out of focus. Considering the direct link between accessibility and focus (Arnold, 2001), the regressive eye-movements performed by participants in the present study seem to provide further evidence towards an accessibility account.

However, this source of evidence is potentially problematic, as it relies on the outcome of the current debate concerning the nature of regressive eye-movements. Although it has widely been accepted that readers make regressive eye-movements on encountering material which is difficulty to integrate (Apel, Henderson \& Ferreira, 2007), the question of whether the region to which participants regress is truly an indication of the cognitive processes underlying sentence processing is a controversial issue.

The selective overt reanalysis model of reading behaviour, initially set forward by Frazier and Rayner (1982), states that participants' eyes are intelligently guided to critical points in a sentence during reading tasks. When processing sentences in which they were required to reanalyse when they had understood so far, participants in Frazier and Rayner's (1982) study displayed eye-movement regressions to the critical regions which needed to be reanalysed. Consequently, the authors concluded that overt eye-movements should be considered informative of the cognitive processes taking place during sentence comprehension in reading tasks. Meseguer, Carreiras and Clifton (2002) more recently found that the strategies employed by readers in the disambiguation of locally ambiguous sentences were reflected in participants' eyemovement patterns. The sentences used in this experiment required participants either to reconsider the main verb of the sentence and its implications for the whole sentence, or to reconsider the adverb which was situated at the onset of the ambiguous part of the sentence, in order to disambiguate the local ambiguity. The eye-tracking data presented two patterns of eye-movement which were consistent with these two disambiguation strategies, namely a bimodal distribution of regressions to the main verb and to the critical adverb. 
Evidence against a linguistic supervision of regressions was however since then claimed by Inhoff and Weger (2005) who reported that participants' regressions systematically fell short of target regions during sentence processing. The regressive eye-movement patterns showed that when spatial memory for the location of a target word failed, participants reached the target words in two successive steps. The first step brought the fixation closer to the target, and the second "homed in on it" (Inhoff, $\&$ Weger, 2005, p 447). Apel, Henderson and Ferreira (2007) clarified this initial observation by demonstrating that target words were not reached within a clean regression sweep, but instead through multiple regression sweeps. However, the size of each saccadic sweep was seen to increase with the distance between the region from which the regression starts and the target region, indicating some influence of spatial memory for the target upon the pattern of regressions. Approximately two thirds of all regressive movements in Apel et al's (2007) study were reported to be one word long, and the remaining third were two words long. These results seem to suggest that, though the target does guide regressions, small regressions of two words or less could be part of a jagged regression sweep rather than linguistically informed regressions to a specific target.

The regression patterns observed in the present study were mostly regressions out from the combined region situated after the pronoun and regressions in to the region of the second name and of the verb of the sentence in the Inconsistent-Post condition. The first pass regressions out of the combined region clearly point towards an early difficulty in integrating the because-clause into the sentence when the subject of the because-clause was a bias-inconsistent pronoun. The combination of a high percentage of regressions out of the combined region and a high percentage of regressions into the name 2 region in condition Inconsistent-Post invites the speculation that readers performed regressive eye-movements from the combined region into the name 2 region, although this pattern was not explicitly analysed. If this were the case, since the sentence structure of the experimental items in the present study was Name1 - verb - Name2 - because - critical - [compound region]...', it could be argued that the regressions into the region of the second name were regressions more than two words. Consequently, in view of Apel et al's (2007) demonstration of one-word or two-word regression steps, it is not implausible that these regressive movements were linguistically guided. They will therefore be considered potentially meaningful in the present analysis. 
The fact that significant differences in patterns of regressions in as well as of second pass reading times was observed between the Consistent-Post condition and the Inconsistent-Post condition only on the region of the second name and not on that of the first name seems at first to be a second cause for concern for the accessibility account. In sentences containing an NP2-bias, the focus would be on the second name, leading to difficulties in retrieving the first name should it prove to be the antecedent of the pronoun after because. Therefore, one would expect sentences containing an NP2-bias verb to display higher second-pass reading times on the first of the two name regions.

Though NP1 and NP2 biases were not analysed separately in the present study, the very high level of significance of the differences between conditions ConsistentPost and Inconsistent-Post observed in second pass reading times on region name 2 and the lack of any significant difference in second pass reading times on region name1 suggests that in both NP1 and NP2-bias sentences participants returned to the name 2 region when the pronoun after because was inconsistent with the verb bias. Further consideration of this observation, in the light of a recent Event-Related Potential study by Nieuwland and Van Berkum (2006) not only enables an explanation of this phenomenon but also refines the accessibility account of the implicit causality effect.

In Nieuwland and Van Berkum's (2006) investigation into the patterns of Event-Related Potentials associated with the processing of a bias-inconsistent pronoun, a significant P600 effect was observed. This effect, generally associated with the processing of sentences containing syntactic violations (Osterhout, 1994), occurred on the presentation of a pronoun which was of the opposite gender to the bias-consistent pronoun. Under the immediate focussing account (Greene \& McKoon, 1995) supported not only by Koornneef and Van Berkum's (2006) data but also by the data of the present investigation, when participants process the pronoun after because, one of the two possible antecedents is already foregrounded as likely centre of the explanation of the event. Almor (1999) stated that, within a coherent discourse, a personal pronoun should only refer to the person who is in focus at the time when the pronoun is encountered. Consequently, participants would interpret the pronoun as referring to the foregrounded antecedent. As such, the P600 effect recorded by Van Berkum et al. (2006) could be interpreted as a reflection of participants interpreting 
the gender of the pronoun as a grammatical error rather than a reflection of a violation of the expectancy of a bias-consistent pronoun. Advocators of linguistically supervised regressive eye-movements have argued that participants regress to the most recent informative point in the sentence (Rayner, \& Pollatsek, 2006). Since the two names placed either side of the implicit-causality verb were systematically of opposite gender, consequently checking the gender of one of the antecedents would necessarily supply the gender of the other antecedent. Consequently, it could be argued that the regressions which were significantly more numerous only to the name 2 region in condition Inconsistent-Post were a means by which participants checked the match between the gender of the person expected to be at the centre of the explanation of the implicit-causality event and the gender of the pronoun featured after because. Thus, the accessibility account need not be threatened by the lack of a significant difference between second pass reading times and regressions in on region name1.

\section{The role of predictions in accessibility}

As stated before, the data collected during the present investigation rejects Koornneef and Van Berkum's (2006) speculation of a word-specific prediction underlying the implicit-causality effect. However, the idea that predictions take place on some level during the processing of implicit-causality sentences is far from excluded. On the contrary, since the accessibility of a given referent has been shown to be "driven by the likelihood that it will be referred to again in the following discourse" (Arnold, 2001, p. 154), predictions seem to form the link between the implicit-causality bias and the accessibility of antecedents.

The likelihood of a future mention is said to be dependent on an interaction between grammatical function and thematic role (Arnold, 2001). Situation models, as defined by Zwaan and Radvansky (1998), encompass information concerning time, space, protagonists, intentionality and, of most relevance to the present investigation, causality. According to Zwaan and Ravansky's (1998) model, on encountering the connector because, comprehenders attempt to "construct a causal connection between the previous event and the incoming event" ( $p$ 171), drawing upon knowledge surrounding the described event. Since verbs with an implicit-causality bias provide information as to who would typically be placed at the centre of an event's explanation, it is not surprising that pronoun resolution in implicit-causality sentences 
is most heavily affected when the explanatory clause is introduced with the connector because (Arnold, 2001). It would appear therefore that, on processing the connector because after an implicit-causality verb, the reader predicts that the discourse entity who would generally be considered responsible for the described event will be the object of the next reference. This in turn raises the accessibility of this antecedent in the reader's memory (Arnold, 2001). The focus on this antecedent necessarily implies that the other antecedent is not in focus (Almor, 1999), resulting in greater processing difficulties for the bias-inconsistent pronoun (Garrod, Greudenthal, \& Boyle, 1994).

\section{Conclusion}

The data reported in the present investigation supports a prediction-based accessibility account, summarised as follows. Based on the semantics of an implicitcausality verb and on world knowledge, participants are able to predict which of the two people mentioned either side of the main verb is likely to be mentioned in an explanation of the event described by this verb. This prediction in turn heightens the focus on one of the two names mentioned in connection with the implicit-causality verb and lessens the focus on the other name. A bias-inconsistent pronoun, which refers back to the name which is not foregrounded, will be difficult to process because its antecedent is not focussed (Garrod, Greudenthal, \& Boyle, 1994) rather than because a bias-consistent pronoun had been predicted in its stead (as suggested by Koornneef and Van Berkum, 2006). On encountering there, no such reshuffle of antecedent accessibility is required, since there is not an anaphoric expression. Consequently, the data of the current experiment suggests that participants predict which of the two discourse entities mentioned either side of the main verb will be mentioned in an explanation of the event, rather than predicting that the word after because will be a bias-consistent pronoun. In favouring conceptual anticipations over word-specific predictions, the findings of the present investigation contribute not only towards a greater understanding the cognitive underpinnings of the implicit-causality effect but also towards the debate concerning the level of detail at which online predictions are made during language comprehension (Weingartner et al., 2003; Van Berkum et al., 2005; Levy, 2005). 


\section{References}

Almor, A. (1999) Noun-phrase Anaphora and focus: the informational load hypothesis. Psychological review, 106:4, 748-765.

Altmann, G. T. M., \& Kamide, Y. (1999). Incremental interpretation at verbs: Restricting the domain of subsequent reference. Cognition, 73,247-264.

Apel, J., Henderson, J.M., \& Ferreira, F. (2007). Targeting Regressions: Do People Pay Attention to the Left. Poster presented at ECEM 14, Potsdam, Germany.

Ariel, M. (1990) Accessing NP antecedents. Routeledge/Cromm Helm.

Arnold, J. (1998) Reference form and discourse patterns. Unpublished doctoral dissertation, Stanford University, Stanford, CA.

Arnold, J. (2001). The effect of thematic roles on pronoun use and frequency of reference continuation. Discourse Processes, 31:2, 137-162.

Brian Roark. 2001a. Probabilistic top-down parsing and language modeling. Computational Linguistics, 27(2), 249-276.

Caramazza, A., Grober, , Garvey, C., \& Yates, J. (1977). Comprehension of anaphoric pronouns. Journal of Verbal Learning and Verbal Behaviour, 16, 601-609.

Chomsky, N. (1957). Syntactic structures. Den Haag, The Netherlands: Mouton.

Chomsky, N. (1995) The minimalist program. MIT.

Crinean, M. \& Garnham, A. (2006) Implicit causality, implicit consequentiality and semantic roles. Language and Cognitive Processes, 21:5, 636-648.

Duffy, S. A., Henderson, J. M., \& Morris, R. K. (1989). Semantic facilitation of lexical access during sentence processing. Journal of Experimental Psychology: Learning, Memory, and Cognition, 15, 791-801.

Ehrlich, S. F., \& Rayner, K. (1981). Contextual effects on word perception and eye movements during reading. Journal of Verbal Learning and Verbal Behavior, $20,641-655$. 
Fincher-Kiefer, R. (1993). The role of predictive inferences in situation model construction. Discourse Processes, 16, 99-124.

Frazier, L. \& Rayner, K. (1982). Making and correcting errors during sentence comprehension: eye-movements in the analysis of structurally ambiguous sentences. Cognitive Psychology, 14, 178-210.

Garnham, A. (2001). Mental models and the interpretation of anaphora. Hove: Psychology Press.

Garrod, S., Freudenthal, D., \& Boyle, (1994). The role of different types of anaphor in the on-line resolution of sentences in a discourse. Journal of Memory and Language, 33(1), 39-68.

Greene, S.B. \& McKoon, G. (1995) Telling something we can't know: Emperimental approaches to verbs exhibiting implicit causality. Psychological science, 6, 262-271.

Hagoort, P. (2003b). The interplay between syntax and semantics during sentence comprehension: ERP effects of combining syntactic and semantic violations. Journal of Cognitive Neuroscience, 15, 883-889.

Hale, J. (2001) The information conveyed by words in sentences. Journal of Psycholinguistic Research, 32(2), 101-123.

Hale, J. (2003). The information conveyed by words in sentences. Journal of Psycholinguistic Research, 32, 101-123.

Hale, J. (2006) Uncertainty about the rest of the sentence. Cognitive Science, 30, 643672.

Harley, T. (2001). The psychology of language: From data to theory. Hove, England: Psychology Press.

Hoeks, J. C., Stowe, L. A., \& Doedens, G. (2004). Seeing words in context: The interaction of lexical and sentence level information during reading. Cognitive Brain Research, 19, 59-73. 
Hoeks, J. C., Stowe, L. A., \& Doedens, G. (2004). Seeing words in context: The interaction of lexical and sentence level information during reading. Cognitive Brain Research, 19, 59-73.

Inhoff, A.W., \& Weger, U.W. (2005). Memory for word location during reading: Eye movements to previously read words are spatially selective but not precise. Memory and Cognition, 33(3), 447-461.

Jackendoff, R. (2002). Foundations of language. New York: Oxford University Press.

Jurafsky, D. (2003) Probabilistic modelling in psycholinguistics: linguistic comprehension and production. In R. Bod, J. Hay and S. Jannedy (Eds) Probabilistic Linguistics. MIT Press.

Kamide, Y., Altmann, G. T. M., \& Haywood, S. L. (2003). The timecourse of prediction in incremental sentence processing: Evidence from anticipatory eye movements. Journal of Memory and Language, 49, 133-156.

Kang, S., Wang, S., Greiner, R., Schuurmans, D, \& Cheng, L. (2004) Exploiting syntactic, semantic and lexical regularities in language modelling via directed Markov random fields. Paper appearing in 2004 International Symposium on Chinese Spoken Language Processing.

Koornneef, A.W. \& Van Berkum, J.J.A. (2006). On the use of verb-based implicit causality in sentence comprehension: Evidence from self-paced reading and eye tracking. Journal of Memory and Language, 54(4), 445-465.

Kutas, M., \& Hillyard, S. A. (1984). Brain potentials during reading reflect word expectancy and semantic association. Nature, 307, 161-163.

Levy, R. (2005). Probabilistic models of word order and syntactic discontinuity. Stanford University.

Long, D.L. \& De Ley, L. (2000). Implicit causality and discourse focus : the interaction of text and reader characteristics in pronoun resolution. Journal of Memory and Language, 42, 545-570. 
Mark, K., Miller, M., \& Granander, U. (1994) Constrained stochastic language models. In. S. Levinson \& L. Shepp (Eds.) Image Models (and their Speech Model Cousins), IMA volumes in Mathematics and its Applications.

McRae, K., Spivey-Knowlton, M. J., \& Tanenhaus, M. K. (1998). Modeling the influence of thematic fit (and other constraints) in on-line sentence comprehension. Journal of Memory and Language, 38, 283-312.

Meseguer, , Carreiras, M., \& Clifton, C.Jr. (2002). Overt reanalysis strategies and eye-movements during the reading of mild garden path sentences. Memory \& Cognition, 30(4), 551-561.

Morris, R.K. \& Folk, J.R. (1998). Focus as contextual priming mechanism in reading. Memory \& Cognition, 26:6, 1313-1322.

Morris, R.K. (2006) Lexical processing and sentence context effects. In M.J. Traxler \& M.A. Gernsbacher (Eds) Handbook of Psycholinguistics (2 ${ }^{\text {nd }}$ Ed.). Academic Press: London.

Nieuwland, M.S., \& Van Berkum, J.J.A. (2006). Individual differences and contextual bias in pronoun resolution: Evidence from ERPs. Brain Research, 1118, 155167.

Osterhout, L. (1994). Event-related brain potentials as tools for comprehending language comprehension. In C. Clifton, Jr., L. Frazier, \& K. Rayner (Eds.), Perspectives on sentence processing. Hillsdale, NJ: Erlbaum.

Otten, M., \& Van Berkum, J. J. A. (2004). Discourse-based lexical anticipation during language processing: Prediction or priming? Annual meeting of the Cognitive Neuroscience Society (CNS-2004), San Francisco, April 18-20. Supplement to the Journal of Cognitive Neuroscience, p. 68.

Pickering, M. J., \& Garrod, S. (2004). Toward a mechanistic psychology of dialogue. Behavioral and Brain Sciences, 27, 1-22.

Rayner, K. \& Pollatsek, A. (2006). Eye Movement Control in Reading. In M.J. Traxler \& M.A. Gernsbacher (Eds) Handbook of Psycholinguistics $\left(2^{\text {nd }}\right.$ Ed.). Academic Press: London. 
Sachs, H., Schegloff, A., \& Jefferson, G. (1974). A simplest systematics for the organization of turn-taking in conversation. Language, 50, 696-735.

Sachs, H., Schegloff, A., \& Jefferson, G. (1974). A simplest systematics for the organization of turn-taking in conversation. Language, 50, 696-735.

Shannon, C., \& Weaver, W. (1949). The mathematical theory of communication. Urbana: University of Illinois Press

Sperber, D., \& Wilson, D. (1986). Relevance: communication and cognition. Cambridge: Harvard University Press.

Stewart, A. J., Pickering, M. J., \& Sanford, A. J. (2000). The time course of the influence of implicit causality information: Focusing versus integration accounts. Journal of Memory and Language, 42, 423-443.

Van Berkum, J.J.A., Brown, C.M., Hagoort, P., \& Zwitserlood, P. (2003). Eventrelated brain potentials reflect discourse-referential ambiguity in spokenlanguage comprehension. Psychophysiology, 40, 235-248.

Van Berkum, J.J.A., Brown, C.M., Zwitserlood, P., Kooijman, V., \& Hagoort, P. (2005). Anticipating upcoming words in discourse: Evidence from ERPs and reading times. Journal of Experimental Psychology: Learning, Memory, \& Cognition, 31(3), 443-467.

Weingartner, K. M., Guzmán, A. , Levine, W. H., \& Klin, C. M. (2003). When throwing a vase has multiple consequences: Minimal encoding of predictive inferences. Discourse Processes, 36, 131-146.

Wicha, N. Y. Y., Moreno, M., \& Kutas, M. (2004). Anticipating words and their gender: An event-related brain potential study of semantic integration, gender expectancy, and gender agreement in Spanish sentence reading. Journal of Cognitive Neuroscience, 16, 1272-1288.

Wilson, K., \& Carroll, J. B. (1954). Applications of entropy measures to problems of sequential structure. In C. Osgood \& T. A. Sebeok (Eds.), Psycholinguistics: a survey of theory and research. Indiana University Press. 
Wilson, K., \& Carroll, J.B. (1954). Psycholinguistics: A survey of theory and research.

Zwaan, R.A., \& Radvansky, G.A. (1998). Situation models in language comprehension and memory. Psychological Bulletin, 123(2), 162-185. 


\section{Appendix - Experimental items}

01.01. Roger lied to Alice because he would clearly not have been hired if the truth had been known.

01.02. Alice lied to Roger because he would clearly not have been impressed with what really happened that day.

01.03. Roger lied to Alice because there would clearly not have been any possibility of friendship if the truth had been known.

01.04. Because he would clearly not have been hired if the truth had been known, Roger lied to Alice.

01.05. Because there would clearly not have been any possibility of friendship if the truth had been known, Roger lied to Alice.

02.01. Nathan annoyed Amelia because he had always been a great tennis player but continuously claimed to be rubbish.

02.02. Amelia annoyed Nathan because he had always been a great supporter of the football team his sister was mocking.

02.03. Nathan annoyed Amelia because there had always been a great discrepancy between their opinions on the scientific status of psychology.

02.04. Because he had always been a great tennis player but continuously claimed to be rubbish, Nathan annoyed Amelia.

02.05. Because there had always been a great discrepancy between their opinions on the scientific status of psychology, Nathan annoyed Amelia.

03.01. Tony apologised to Anne because he had most definitely been a major contributor to the tensions in the office.

03.02. Anne apologised to Tony because he had most definitely been a victim of the nasty rumour the girls had spread around the office.

03.03. Tony apologised to Anne because there had most definitely been a longer delay in the delivery this time.

03.04. Because he had most definitely been a major contributor to the tensions in the office, Tony apologised to Anne.

03.05. Because there had most definitely been a longer delay in the delivery this time, Tony apologised to Anne. 
04.01. Bradley upset Caitlin because he was quite surprisingly and unnecessarily rude in turning down an invitation to the prom.

04.02. Caitlin upset Bradley because he was quite surprisingly and unnecessarily sensitive during the last committee meeting.

04.03. Bradley upset Caitlin because there was quite surprisingly and unnecessarily a lot of sarcasm in a few comments about the flower arrangements

04.04. Because he was quite surprisingly and unnecessarily rude in turning down an invitation to the prom, Bradley upset Caitlin.

04.05. Because there was quite surprisingly and unnecessarily a lot of sarcasm in a few comments about the flower arrangements, Bradley upset Caitlin.

05.01. Owen misled Ella because he was possibly one of the biggest flirts in the school.

05.02. Ella misled Owen because he was possibly one of the least wary boys in the school.

05.03. Owen misled Ella because there was possibly one of the greatest misunderstandings about an innocent remark.

05.04. Because he was possibly one of the biggest flirts in the school, Owen misled Ella.

05.04.Q.L. Who was mentioned in the last sentence? Ella Cinderella

05.05. Because there was possibly one of the greatest misunderstandings about an innocent remark, Owen misled Ella.

06.01. Ryan charmed Emma because he had recently been much more well-behaved and seemed to have become a gentleman.

06.02. Emma charmed Ryan because he had recently been much more attracted to women with great personalities.

06.03. Ryan charmed Emma because there had recently been much more romance in their otherwise unremarkable relationship.

06.04. Because he had recently been much more well-behaved and seemed to have become a gentleman, Ryan charmed Emma.

06.05. Because there had recently been much more romance in their otherwise unremarkable relationship, Ryan charmed Emma. 
07.01. Lewis bored Grace because he could not possibly have been less interesting if he had tried.

07.02. Grace bored Lewis because he could not possibly have been less interested in the social life of her pet seagull.

07.03. Lewis bored Grace because there could not possibly have been anything less exciting than hearing once again about the latest developments in pronoun research.

07.04. Because he could not possibly have been less interesting if he had tried, Lewis bored Grace.

07.05. Because there could not possibly have been anything less exciting than hearing once again about the latest developments in pronoun research, Lewis bored Grace.

08.01. Harry peeved Helen because he had always been a little bit too sure of himself. 08.02. Helen peeved Harry because he had always been a little jealous of people with perfect hair.

08.03. Harry peeved Helen because there had always been a little too much tension between their families.

08.04. Because he had always been a little bit too sure of himself, Harry peeved Helen.

08.05. Because there had always been a little too much tension between their families, Harry peeved Helen.

09.01. Alexander alarmed Isabella because he had recently without a doubt lost a lot of weight.

09.02. Isabella alarmed Alexander because he had recently without a doubt noticed the young girl's severe weight loss.

09.03. Alexander alarmed Isabella because there had recently without a doubt been very disturbing rumours spreading throughout the hospital.

09.04. Because he had recently without a doubt lost a lot of weight, Alexander alarmed Isabella.

09.05. Because there had recently without a doubt been very disturbing rumours spreading throughout the hospital, Alexander alarmed Isabella. 
10.01. Henry infuriated Jenny because he was without fail at least half an hour late to every single meeting.

10.02. Jenny infuriated Henry because he was without fail at least twice as hard working as his female counterpart was in every joint project.

10.03. Henry infuriated Jenny because there was without fail at least one mistake in all the budget reports.

10.04. Because he was without fail at least half an hour late to every single meeting, Henry infuriated Jenny.

10.05. Because there was without fail at least one mistake in all the budget reports, Henry infuriated Jenny.

11.01. Bruce intimidated Julie because he was possibly one of the tallest people in Europe.

11.02. Julie intimidated Bruce because he was possibly one of the least confident people around.

11.03. Bruce intimidated Julie because there was possibly one of the darkest looks on the film star's face during the whole interview.

11.04. Because he was possibly one of the tallest people in Europe, Bruce intimidated Julie.

11.05. Because there was possibly one of the darkest looks on the film star's face at all times, Bruce intimidated Julie.

12.01. Ethan irritated Katie because he had almost certainly been more critical than was necessary.

12.02. Katie irritated Ethan because he had almost certainly been more involved in the project than the people who did receive an acknowledgement.

12.03. Ethan irritated Katie because there had almost certainly been more sarcasm than sincerity in every single remark.

12.04. Because he had almost certainly been more critical than was necessary, Ethan irritated Katie.

12.05. Because there had almost certainly been more sarcasm than sincerity in every single remark, Ethan irritated Katie. 
13.01. Jake captivated Katy because he was somehow suddenly a lot more attractive than on previous occasions.

13.02. Katy captivated Jake because he was somehow suddenly a lot more aware of how beautiful the young lady was.

13.03. Jake captivated Katy because there was somehow suddenly a lot more depth to the young lad's personality.

13.04. Because he was somehow suddenly a lot more attractive than on previous occasions, Jake captivated Katy.

13.05. Because there was somehow suddenly a lot more depth to the young lad's personality, Jake captivated Katy.

14.01. Alison confessed to Trevor because she had lately been more and more crushed by guilt.

14.02. Trevor confessed to Alison because she had lately been more and more suspicious about the whole situation.

14.03. Alison confessed to Trevor because there had lately been more and more incriminating evidence.

14.04. Because she had lately been more and more crushed by guilt, Alison confessed to Trevor.

14.05. Because there had lately been more and more incriminating

evidence, Alison confessed to Trevor.

15.01. Angela called George because she had somehow recently been a bit too scared to talk to anyone else.

15.02. George called Angela because she had somehow recently been a great support. 15.03. Angela called George because there had somehow recently been a very exciting development in the life of one of their friends.

15.04. Because she had somehow recently been a bit too scared to talk to anyone else, Angela called George.

15.05. Because there had somehow recently been a very exciting development in the life of one of their friends, Angela called George.

16.01. Barbara telephoned Michael because she had very recently been extremely rude and wanted to apologise. 
16.02. Michael telephoned Barbara because he had very recently been extremely ill and was in need of some moral support.

16.03. Barbara telephoned Michael because there had very recently been extremely exciting news that needed to be shared.

16.04. Because she had very recently been extremely rude and wanted to apologise, Barbara telephoned Michael.

16.05. Because there had very recently been extremely exciting news that needed to be shared, Barbara telephoned Michael.

17.01. Eleanor exasperated Cameron because she had quite clearly never been as amazing as all the boasting seemed to suggest.

17.02. Cameron exasperated Eleanor because he had quite clearly never been able to understand women.

17.03. Eleanor exasperated Cameron because there had quite clearly never been any hope of cooperation.

17.04. Because she had quite clearly never been as amazing as all the boasting seemed to suggest, Eleanor exasperated Cameron.

17.05. Because there had quite clearly never been any hope of cooperation, Eleanor exasperated Cameron.

18.01. Emily amused James because she had always seemed to be gifted in the art of telling jokes.

18.02. James amused Emily because she had always seemed to be the type to find poor jokes hilarious.

18.03. Emily amused James because there had always seemed to be something funny about tone-deaf opera singers.

18.04. Because she had always seemed to be gifted in the art of telling jokes, Emily amused James.

18.05. Because there had always seemed to be something funny about tone-deaf opera singers, Emily amused James.

19.01. Georgia enraged Matthew because she had evidently never ever been able to admit to being wrong. 
19.02. Matthew enraged Georgia because she had evidently never ever been able to keep calm.

19.03. Georgia enraged Matthew because there had evidently never ever been any acknowledgement of a shared responsibility in the accident.

19.04. Because she had evidently never ever been able to admit to being wrong, Georgia enraged Matthew.

19.05. Because there had evidently never ever been any acknowledgement of a shared responsibility in the accident, Georgia enraged Matthew.

20.01. Hannah angered Daniel because she had clearly never ever been able to listen to people without interrupting them.

20.02. Daniel angered Hannah because she had clearly never ever been able to stay calm when criticised.

20.03. Hannah angered Daniel because there had clearly never ever been any apologies made for the death of the bonsai tree.

20.04. Because she had clearly never ever been able to listen to people without interrupting them, Hannah angered Daniel.

20.05. Because there had clearly never ever been any apologies made for the death of the bonsai tree, Hannah angered Daniel.

21.01. Holly scared Alfie because she had always been a notoriously violent person.

21.02. Alfie scared Holly because she had always been a notoriously shy person.

21.03. Holly scared Alfie because there had always been a notoriously scary rumour going round the school.

21.04. Because she had always been a notoriously violent person, Holly scared Alfie.

21.05. Because there had always been a notoriously scary rumour going round the school, Holly scared Alfie.

22.01. Jennifer disappointed Jonathan because she had evidently never truly been able to keep a promise.

22.02. Jonathan disappointed Jennifer because she had evidently never truly been treated with such contempt before.

22.03. Jennifer disappointed Jonathan because there had evidently never truly been any desire to keep any promises. 
22.04. Because she had evidently never truly been able to keep a promise, Jennifer disappointed Jonathan.

22.05. Because there had evidently never truly been any desire to keep any promises, Jennifer disappointed Jonathan.

23.01. Kate worried Greg because she had slowly but surely been getting more and more depressed about life.

23.02. Greg worried Kate because she had slowly but surely been noticing more and more behavioural oddities.

23.03. Kate worried Greg because there had slowly but surely been a decline in the young patient's mental faculties.

23.04. Because she had slowly but surely been getting more and more depressed about life, Kate worried Greg.

23.05. Because there had slowly but surely been a decline in the young patient's mental faculties, Kate worried Greg.

24.01. Jessica deceived Richard because she would definitely not have been able to complete the mission otherwise.

24.02. Richard deceived Jessica because she would definitely not have been safe if the superhero's secret identity had been known.

24.03. Jessica deceived Richard because there would definitely not have been any other way of preventing the truth from spreading.

24.04. Because she would definitely not have been able to complete the mission otherwise, Jessica deceived Richard.

24.05. Because there would definitely not have been any other way of preventing the truth from spreading, Jessica deceived Richard.

25.01. Julie followed Barry because she had recently been much more prone to stalking people.

25.02. Barry followed Julie because she had recently been much more secretive about the locations of the WI meetings.

25.03. Julie followed Barry because there had recently been much more reason to suspect something fishy was going on. 
25.04. Because she had recently been much more prone to stalking people, Julie followed Barry.

25.05. Because there had recently been much more reason to suspect something fishy was going on, Julie followed Barry.

26.01. Harvey sacked Lauren because she had most certainly never been as qualified as the CV had implied.

26.02. Lauren sacked Harvey because she had most certainly never been happy with the new recruit's performance.

26.03. Harvey sacked Lauren because there had most certainly never been any sign of an effort to fit in with the rest of the team.

26.04. Because she had most certainly never been happy with the new recruit's performance, Lauren sacked Harvey.

26.05. Because there had most certainly never been any sign of an effort to fit in with the rest of the team, Harvey sacked Lauren.

27.01. Kevin admired Julia because she was undeniably one of the most sophisticated people in town.

27.02. Julia admired Kevin because she was undeniably one of the easiest people to please.

27.03. Kevin admired Julia because there was undeniably one of the best reasons to do so.

27.04. Because she was undeniably one of the easiest people to please, Julia admired Kevin.

27.05. Because there was undeniably one of the best reasons to do so, Kevin admired Julia.

28.01. Jack was fond of Lucy because she had evidently always been incredibly kind as well as being pretty.

28.02. Lucy was fond of Jack because she had evidently always been incredibly attracted to people with a good sense of humour.

28.03. Jack was fond of Lucy because there had evidently always been incredibly similar traits to their personalities. 
28.04. Because she had evidently always been incredibly attracted to people with a good sense of humour, Lucy was fond of Jack.

28.05. Because there had evidently always been incredibly similar traits to their personalities, Jack was fond of Lucy.

29.01. Thomas was jealous of Maggie because she had clearly always been the most popular member of the chess club.

29.02. Maggie was jealous of Thomas because she had clearly always been the less popular of the two.

29.03. Thomas was jealous of Maggie because there had clearly always been the most horrendous competition between them.

29.04. Because she had clearly always been the less popular of the two, Maggie was jealous of Thomas.

29.05. Because there had clearly always been the most horrendous competition between them, Thomas was jealous of Maggie.

30.01. Ben scolded Mia because she had most definitely been very unnecessarily rude to the teacher that day.

30.02. Mia scolded Ben because she had most definitely been very clear about not insulting teachers in the past.

30.03. Ben scolded Mia because there had most definitely been very alarming remarks made by the head teacher.

30.04. Because she had most definitely been very clear about not insulting teachers in the past, Mia scolded Ben.

30.05. Because there had most definitely been very alarming remarks made by the head teacher, Ben scolded Mia.

31.01. Timothy adored Miranda because she was unequivocally one of the most beautiful women on the planet.

31.02. Miranda adored Timothy because she was unequivocally one of the greatest fans of jazz flute.

31.03. Timothy adored Miranda because there was unequivocally one of the tastiest cakes in the old lady's house at all times. 
31.04. Because she was unequivocally one of the greatest fans of jazz flute, Miranda adored Timothy.

31.05. Because there was unequivocally one of the tastiest cakes in the old lady's house at all times, Timothy adored Miranda.

32.01. Peter thanked Nancy because she had undoubtedly been one of the most helpful people on the team during the last difficult month.

32.02. Nancy thanked Peter because she had undoubtedly been one of the beneficiaries of the company's new policies on maternity leave.

32.03. Peter thanked Nancy because there had undoubtedly been one of the greatest changes in the morale of the troops since the team-building session.

32.04. Because she had undoubtedly been one of the beneficiaries of the company's new policies on pay during maternity leave, Nancy thanked Peter.

32.05. Because there had undoubtedly been one of the greatest changes in the morale of the troops since the team-building session, Peter thanked Nancy.

33.01. Jason was terrified of Polly because she had very recently seemed to get alarmingly angry over fairly minor issues.

33.02. Polly was terrified of Jason because she had very recently seemed to develop an irrational fear of men with beards.

33.03. Jason was terrified of Polly because there had very recently seemed to be a very eerie atmosphere in the office.

33.04. Because she had very recently seemed to develop an irrational fear of men with beards, Polly was terrified of Jason.

33.05. Because there had very recently seemed to be a very eerie atmosphere in the office, Jason was terrified of Polly.

34.01. William noticed Rebecca because she had suddenly seemed to be making more of an effort to dress well.

34.02. Rebecca noticed William because she had suddenly seemed to be more attentive to the looks of her peers. 
34.03. William noticed Rebecca because there had suddenly seemed to be a remarkable beauty in the young girl's looks.

34.04. Because she had suddenly seemed to be more attentive to the looks of her peers, Rebecca noticed William.

34.05. Because there had suddenly seemed to be a remarkable beauty in the young girl's looks, William noticed Rebecca.

35.01. Tommy envied Sally because she had always seemed to be the one that people remembered.

35.02. Sally envied Tommy because she had always seemed to be the one nobody remembered.

35.03. Tommy envied Sally because there had always seemed to be a lot of favouritism towards his sister.

35.04. Because she had always seemed to be the one nobody remembered, Sally envied Tommy.

35.05. Because there had always seemed to be a lot of favouritism towards his sister, Tommy envied Sally.

36.01. Andrew loathed Sheila because she had systematically seemed to be the one to ask the tricky question.

36.02. Sheila loathed Andrew because she had systematically seemed to be ridiculed in board meetings.

36.03. Andrew loathed Sheila because there had systematically seemed to be a feminist agenda behind every snide comment.

36.04. Because she had systematically seemed to be ridiculed in board meetings, Sheila loathed Andrew.

36.05. Because there had systematically seemed to be a feminist agenda behind every snide comment, Andrew loathed Sheila.

37.01. David congratulated Susan because she had clearly seemed to be the strongest candidate in this difficult competition.

37.02. Susan congratulated David because she had clearly seemed to be keen to encourage both successful and unsuccessful candidates in this difficult competition. 
37.03. David congratulated Susan because there had clearly seemed to be a lot of competition for this job.

37.04. Because she had clearly seemed to be keen to encourage both successful and unsuccessful candidates in this difficult competition, Susan congratulated David.

37.05. Because there had clearly seemed to be a lot of competition for this job, David congratulated Susan.

38.01. Laura thought highly of Aaron because he had always been the greatest of friends.

38.02. Aaron thought highly of Laura because he had always been the greatest admirer of stupidly intelligent people.

38.03. Laura thought highly of Aaron because there had always been the greatest humility in the old man's statements.

38.04. Because he had always been greatest admirer of stupidly intelligent people, Aaron thought highly of Laura.

38.05. Because there had always been the greatest humility in every one the old man's statements, Laura thought highly of Aaron.

39.01. Leah fired Adam because he had somewhat inexplicably lately been one of the least efficient members of staff.

39.02. Adam fired Leah because he had somewhat inexplicably lately been told to get rid of ten members of staff.

39.03. Leah fired Adam because there had somewhat inexplicably lately been a major financial loss in the company.

39.04. Because he had somewhat inexplicably lately been told to get rid of 10 members of staff, Adam fired Leah.

39.05. Because there had somewhat inexplicably lately been a major financial loss in her company, Leah fired Adam.

40.01. Louise respected Donald because he was without question a lot wiser than most of the other members of staff.

40.02. Donald respected Louise because he was without question a lot more reverent than most of the men in the team. 
40.03. Louise respected Donald because there was without question a lot of wisdom in the comments about the design.

40.04. Because he was without question a lot more reverent than most of the men in the team, Donald respected Louise.

40.05. Because there was without question a lot of wisdom in the comments about the design, Louise respected Donald.

41.01. Mary detested John because he had always seemed to be extremely arrogant.

41.02. John detested Mary because he had always seemed to be incapable of forgiving anyone.

41.03. Mary detested John because there had always seemed to be an injustice about the way their disagreement was handled.

41.04. Because he had always seemed to be incapable of forgiving anyone, John detested Mary.

41.05. Because there had always seemed to be an injustice about the way their disagreement was handled, Mary detested John.

42.01. Megan was scared of Jacob because he had always been a very angry man.

42.02. Jacob was scared of Megan because he had always been a very timid man.

42.03. Megan was scared of Jacob because there had always been a very creepy rumour about the old man.

42.04. Because he had always been a very timid man, Jacob was scared of Megan.

42.05. Because there had always been a very creepy rumour about the old man, Megan was scared of Jacob.

43.01. Millie liked Connor because he had without a doubt never said anything unkind to anyone.

43.02. Connor liked Millie because he had without a doubt never seen her being horrible to anyone.

43.03. Millie liked Connor because there had without a doubt never been any reason not to.

43.04. Because he had without a doubt never seen her being horrible to anyone, Connor liked Millie. 
43.05. Because there had without a doubt never been any reason not to, Millie liked Connor.

44.01. Molly resented Dylan because he didn't ever seem to be there when there was a crisis.

44.02. Dylan resented Molly because he didn't ever seem to be thanked for anything.

44.03. Molly resented Dylan because there didn't ever seem to be any question of coming to a compromise.

44.04. Because he didn't ever seem to be thanked for anything, Dylan resented Molly.

44.05. Because there didn't ever seem to be any question of coming to a compromise,

Molly resented Dylan.

45.01. Olivia hated Samuel because he had never seemed to be able to refrain from making crude jokes.

45.02. Samuel hated Olivia because he had never seemed to be able to get on with people who wear green socks.

45.03. Olivia hated Samuel because there had never seemed to be any way of getting on with such a monster.

45.04. Because he had never seemed to be able to like people who wear green socks, Samuel hated Olivia.

45.05. Because there had never seemed to be any way of getting on with such a monster, Olivia hated Samuel.

46.01. Ruby approved of Luke because he was possibly one of the most sensible boys on the council estate.

46.02. Luke approved of Ruby because he was possibly one of the least difficult fathers-in-law to please.

46.03. Ruby approved of Luke because there was possibly one of the nicest and most sensible airs about the young lad.

46.04. Because he was possibly one of the least difficult fathers-in-law to please, Luke approved of Ruby.

46.05. Because there was possibly one of the nicest and most sensible airs about the young lad, Ruby approved of Luke. 
47.01. Rachel disapproved of Gordon because he had truly been quite badly behaved at the last garden party.

47.02. Gordon disapproved of Rachel because he had truly been quite badly hurt by similar women in the past.

47.03. Rachel disapproved of Gordon because there had truly been quite badly constructed sentences the candidate's speech.

47.04. Because he had truly been quite badly hurt by similar women in the past, Gordon disapproved of Rachel.

47.05. Because there had truly been quite badly constructed sentences in the candidate's speech, Rachel disapproved of Gordon.

48.01. Sarah was grateful to Frank because he had definitely been one of the best mentors one could ever hope to have.

48.02. Frank was grateful to Sarah because he had definitely been one of the many people who had most benefited from the patroness's generous donation.

48.03. Sarah was grateful to Frank because there had definitely been one of the best atmospheres in the office since the young psychologist's recent intervention.

48.04. Because he had definitely been one of the many people who had most benefited from the generous donation, Frank was grateful to Sarah.

48.05. because there had definitely been one of the best atmospheres in the office since the young psychologist's recent intervention, Sarah was grateful to Frank.

49.01. Sophie praised Joshua because he was possibly one of the best-dressed men to have ever entered the office.

49.02. Joshua praised Sophie because he was possibly one of the most fervent admirers of women with pink shoes.

49.03. Sophie praised Joshua because there was possibly one of the most fashionable shirts in the young man's wardrobe.

49.04. Because he was possibly one of the most fervent admirers of women with pink shoes, Joshua praised Sophie.

49.05. Because there was possibly one of the most fashionable shirts in the young man's wardrobe, Sophie praised Joshua. 
50.01. Victoria paid tribute to Nicholas because he had lately unmistakably been a key contributor to the financial viability of the firm.

50.02. Nicholas paid tribute to Victoria because he had lately unmistakably been a bit too keen to thank absolutely everybody who had worked on the project.

50.03. Victoria paid tribute to Nicholas because there had lately unmistakably been a lot of progress made thanks to some very insightful comments.

50.04. Because he had lately unmistakably been a bit too keen to thank absolutely everybody who had worked on the project, Nicholas paid tribute to Victoria.

50.05. Because there had lately unmistakably been a lot of progress made thanks to some very insightful comments, Victoria paid tribute to Nicholas. 